\title{
A Comprehensive Survey of Optimal Placement and Coordinated Control Techniques of FACTS Controllers in Multi-Machine Power System Environments
}

\begin{abstract}
Bindeshwar Singh $^{\dagger}$, N. K. Sharma* and A. N. Tiwari**
Abstract - This paper presents exhaustive review of various methods/techniques for coordinated control between FACTS controllers in multi-machine power systems. It also reviews various techniques/methods for optimal choice and allocation of FACTS controllers. Authors strongly believe that this survey article will be very much useful to the researchers for finding out the relevant references in the field of placement and coordination of FACTS Controllers.
\end{abstract}

Keywords: Control Coordination, Flexible AC Transmission System (FACTS), FACTS Controllers, Interactions, Placements, Voltage Stability

\section{Introduction}

The drive towards deregulated environment may result in simultaneous installation of different FACTS controllers in power system. These multiple FACTS controllers have the potential to interact with each other. This interaction may either deteriorate or enhance system stability depending upon the chosen controls and placement of FACTS controllers. Hence there is a need to study the interaction between the FACTS controllers.

The various interactions can potentially occur between the different FACTS controllers, as well as, between FACTS controllers and Power System Stabilizers (PSS) in a multi-machine power system environment. These likely interactions have been classified into different frequency ranges and various interaction problems between FACTS controllers or FACTS to PSS's from voltage stability/ small signal stability viewpoint are presented in [1]-[2].

There are several methods proposed in literatures [3][86], [157]-[180], [201], for placement of FACTS controllers in multi-machine power systems from different operating conditions viewpoint. References [3]-[5], classify three broad categories such as a sensitivity based methods, optimization based method, and artificial intelligence based techniques for placement of FACTS controllers from different operating conditions viewpoint in multi-machine power systems. The various sensitivity based methods have been proposed in literatures includes eigen-value analysis based methods [6]-[12], modal analysis techniques [13][15], index methods [16]-[23], residue-based methods [24][25], [43], [168], [169], and other sensitivity based meth-

$\dagger \quad$ Corresponding Author: Dept. of Electrical Engineering, Kamla Nehru Institute of Technology, Sultanpur-228118 (U.P.), India

(bindeshwar.singh2025@gmail.com)

* Dept. of Electrical Engineering, Raj Kumar Goel Engineering College, Ghaziabad (U.P.), India (drnikhlesh@gmail.com)

* Dept. of Electrical Engineering, Madan Mohan Malviya Engineering College, Gorakhpur-273010 (U.P.), India (amerndee@rediffmail.com)

Received : November 16, 2009; Accepted : January 4, 2010 ods [26]-[37], [53], [157]-[167], [201].

The various optimization based methods have been proposed in literatures that includes non-linear optimization programming techniques [38], [39], [173], mixed integeroptimization programming techniques [40]-[42], [170][171], dynamic optimization programming algorithms [44], hybrid optimization programming algorithms [45], bellmann's optimization principle [46], decomposition coordination methods [47]-[48], curved space optimization techniques [174]. The various artificial intelligence (AI) based methods proposed in literature includes genetic algorithms (GA) [49]-[64], [175]-[176], [180], tabu search algorithms [65], [66], simulated annealing (SA) based approach [69][70], [177], particle swarm optimization (PSO) techniques [71]-[73], [80], artificial neural network (ANN) based algorithms [74]-[76], ant colony optimization (ACO) algorithms [77]-[78], graph search algorithms [79], fuzzy logic based approach [81]-[82], other techniques such as norm forms of diffeomorphism techniques [83], evolution strategies algorithms [84], [86], improved evolutionary programming [68], gravitational optimization techniques [85], benders decomposition techniques [42], augmented Lagrange multiplier approach [67], hybrid meta-heuristic approach [172], heuristic and algorithmic approach [178], energy approach [179].

There are several methods proposed in literatures for coordination of multiple FACTS controllers in multi-machine power systems from different operating conditions viewpoint [11], [25], [87]-[156], [181]-[200], [202]-[212]. Three broad categories such as a sensitivity based methods, optimization based method and artificial intelligence based techniques for coordination of FACTS controllers from different operating conditions in multi-machine power systems is classified in [5]. The various sensitivity based methods have been proposed in literatures includes eigenvalue analysis based methods [11], [88]-[96], [181]-[182], modal analysis techniques [97]-[103], residue-based methods [104], [105]. There are various other techniques such 
as a pole placement techniques [106], frequency response techniques [107], root locus techniques [108], projective control methods [109]-[111], [200], non-linear feed control methods [112]-[113] for coordination of FACTS controllers and PSS. The various optimization based methods have been proposed in literatures for coordination includes a dynamic optimization programming algorithms [128], nonlinear optimization programming techniques [129]-[133], [184], linear optimization programming techniques [134][136], [183], [203]-[204], [206]-[207], [210], immune-based optimization algorithms[137]. The various artificial intelligence (AI) based methods have been proposed in literatures that includes a genetic algorithms (GA) [144]-[147], [185], [186], [209], tabu search algorithms [148], [187], simulated annealing (SA) based approach [149], particle swarm optimization (PSO) techniques [150], [190], [205], artificial neural networks (ANN) based algorithms [[151], [202],fuzzy logic based approach [152]-[155], [188]-[189], [212], adaptive neuro-fuzzy inference system (ANIS) techniques [156], H-infinity optimization techniques [191]-[193], $\mu$-synthesis techniques [194]-[196], linear matrix inequality technique [197], prony methods [198], riccati equations methods [199], relative gain array (RGA) theory [208], load flow control technique [211].

This paper is organized as follows: Section II discusses the types of interactions between FACTS controllers in multi-machine power systems. Section III presents the review of various techniques/methods for placements of FACTS controllers in multi-machine power systems. Section IV presents the review of various techniques/methods for coordination of multiple FACTS controllers in multimachine power systems. Section V presents the summary of the paper. Section VI presents the conclusions of the paper.

\section{Interactions between Multiple Facts Controllers}

Types of Interactions of FACTS Controllers are presented in [1] includes

- Multiple FACTS controllers of a similar type

- Multiple FACTS controllers of a dissimilar type

- Multiple FACTS controllers and HVDC converter controllers

The various interactions that can potentially occur between the different FACTS controllers, as well as between FACTS and PSS's or HVDC controllers, in power system environments have been classified into different frequency ranges. The frequency ranges of the different control interactions have been classified includes [2]

- $0 \mathrm{~Hz}$ for steady state interactions

- $0-3 / 5 \mathrm{~Hz}$ for electro-mechanical oscillations

- 2-15 Hz for small-signal or control oscillations

- 10-50/60 Hz for sub -synchronous resonance (SSR) interaction

- $>15 \mathrm{~Hz}$ for electromagnetic transients, high frequency resonance or harmonic resonance interactions
In [2] two methods have been proposed to solve interaction phenomenon between dynamic loads and FACTS controllers in power systems. The first one is based on sensitivity and residues techniques and it takes into account the uncertain character of dynamic loads to compute the most efficient phase compensation for low frequency oscillations damping. The second approach consists on designing a robust damping controller by Linear Matrix Inequalities (LMI) techniques which gives a certain degree of stability and performances of the FACTS controllers in presence of dynamic loads uncertainties.

\section{Classification of Facts Controllers Allocation Techniques}

Three broad categories of allocation techniques for determining best suited location of FACTS controllers are sensitivity based methods, optimization based method, and artificial intelligence based techniques [3]-[5].

\subsection{Sensitivity Based Methods}

There are various sensitivity based methods such as a modal or eigen-value and index analysis. The problem of improving the dynamic stability of power systems by means of supplementary stabilizers has received considerable attention in the literatures. This literature is concerned specifically with this problem. This problem is solved in literature, an eigen-value analysis based techniques has been proposed in [6] for the selection of parameters of stabilizers in multi-machine power system to enhance the damping of the power system oscillations. Reference [7], presents an eigen-value analysis based algorithms such as a participation factor method for identification of optimum location of power system stabilizers to enhance the damping of power system oscillations. Many literatures shows the existing methods of identifying the optimum sites for installing PSSs in multi-machine power systems are restricted to the sequential PSS application, which considers the enhancement of damping of just one critical electro-mechanical modes at a time and the eigen structure analysis of the open loop system, which does not take the control matrix (the B matrix in the linearized model $\mathrm{dX} / \mathrm{dt}=\mathrm{AX}+\mathrm{BU}$ for power system) into considerations. An eigen-value analysis based techniques has been proposed for identifying the optimum sites for installing power system stabilizers (PSSs) in multimachine power systems in [8]. The advantages of this proposed method is that it can identify the optimum sites for installing PSS so that several electro-mechanical modes are damped out simultaneously and it takes both the eigen structure of the open loop system and the control matrix into consideration. Reference [9], suggests an eigen-value analysis based approach for identifying the most effective FACTS controllers, locations, types and ratings that increase asset utilization of power systems. The application of this presented approach in literature on representative studied transmission system has resulted in an increase of the 
maximum stable loadability limit by $6.7 \%$. This literature finally shows that the proposed approach is helpful in coordinating the functionality of FACTS controllers to enhance power system dynamics. The location of SVC and other types of shunt compensation devices for voltage support is an important practical question. This literature considers a tool based on the determination of critical modes. Reference [10], uses participation factor method has been suggested for the critical mode is used to determine the most suitable sites for SVC (Static Var Compensator) for system reinforcement. Voltage collapses typically occurs on power systems that are heavily loaded, faulted and/or have reactive power shortage. Voltage collapse is system instability in that it involves many power system components and their variable at once. Indeed, voltage collapse often involves an entire power system, although it usually has a relatively larger involvement in one particular area of the power system is presented in many literatures. In [11]-[12], an eigenvalue analysis based approach has been proposed for find the optimal location and rating of FACTS controllers (Static Var Compensator (SVC) and Thyristor Controlled Series Controller(TCSC)) and a continuation power flow is used to evaluate the effects of SVC and TCSC devices on power system loadability). FACTS controllers are recognized as a new damping resource for poorly damped, low frequency electromechanical oscillation, which usually takes place in a power system operating with long transmission lines under heavily loaded condition. Nevertheless, the damping effect of FACTS controllers is known to be strongly influenced by their location and control system. This literature is motivated to cope with these two challenges. In [13], a modal analysis algorithm has been suggested for allocation and control of FACTS devices for steady-state stability enhancement of large scale power system. Many literatures studies have been carried out on the use of FACTS devices for voltage and angle stability problems. These problems are study in literature, a modal analysis algorithm has been suggested for placement of SVCs and selection of stability signals in power systems environments [14]. A new eigen solution free method of modal control analysis for the selection of the robust installing locations and feedback signals of FACTS based stabilizers in large-scale power systems is presented in [15]. Many literatures studies have made it clear that variable impedance apparatus such as a static Var compensator (SVC) and a variable series capacitor ( $\mathrm{VSrC}$ ) can improve the steady-state stability (or the small signal stability). Therefore, it is important for the power system planners to determine the effective location of SVCs and VSrCs. For large power system networks, it is difficult and time consuming to identify the effective location through a number of digital simulations and eigen-value analyses. For this reason, the efficient method for finding the location is desired. An index based approach known as a Location Index for Effective Damping (LIED) method has been proposed for identifying the location of SVC and a Variable Series Capacitor (VSrC) in large-scale power systems for damping effectively in [16]. A structure preserving energy mar- gin sensitivity based analysis has been addressed for determine the effectiveness of FACTS devices to improve transient stability of a power system in [17]. A controllability index method has been proposed for select the input signals for both single and multiple FACTS devices in small and large power systems for damping inter-area oscillations in [18]. Different input output controllability analysis are used to asses the most appropriate input signals (stability signals) for the SVC, the Static Synchronous Series Compensator (SSSC) and the Unified Power Flow Controller (UPFC) for achieving good damping of interarea oscillations. Due to ever increasing load demand and reduced rights of ways, modern power transmission systems are forced to carry increasingly more power over long distances. Consequently, the transmission system becomes more stressed, which, in turn, makes the system more vulnerable to voltage stability and security problems. Such problems are minimized in literature, a new method called the Extended Voltage Phasors Approach (EVPA) has been suggested for placement of FACTS controllers in power systems for identifying the most critical segments/bus in power system from the voltage stability view point in [19]. In [20]-[23], an index based method has been addressed for determine the suitable locations of FACTS devices in power system environments. A residues based approach has been proposed for allocation of FACTS controllers in power system to enhance the system stability [24]-[25]. An efficient algorithm for the solution of two important problems in the area of damping control of electro-mechanical oscillations in large scale power systems has been proposed in [26]. The proposed algorithms allow the determination the most suitable generators for installing power system stabilizers and the most suitable buses in the system for placing SVC in order to damp the critical modes of oscillation. A sensitivity based approach has been proposed for placement of FACTS controllers in open power markets to reduce the flows in heavily loaded lines, resulting in an increased loadability, low system loss, improved stability of the network, reduced cost of production and fulfilled contractual requirement by controlling the power flows in the network in [27]-[28]. Voltage collapse, as a consequence of voltage instability, has been a matter of great concern for researchers and utilities since last two decades. Research efforts have been made in understanding the phenomenon associated with the voltage instability and suggesting the remedial measures to protect the power system networks against such failures. Curtailment of loads has been suggested in many literatures to save the system against voltage collapse. A sensitivity based approach called Bus Static Participation Factor (BSPF) has been proposed for determine the optimal location of static VAR compensator (SVC) for voltage security enhancement in [29]. A sensitivity based approach has been proposed to determine the placement of TCSC and UPFC for enhancing the power system loadability [30]. In [31], a sensitivity analysis method has been proposed for determine the optimal placement of static VAR compensator (SVC) for voltage security enhancement in Algerian Distribution System. 
In [32], a sensitivity analysis and evolutionary programming techniques has been proposed for determine the optimal placement of UPFC in power system from the operational planning viewpoint. Sensitivity analysis is superior when compared to the others as sensitivity analysis gives the best possible installation location. In recent years an instability usually termed voltage instability has been responsible for several major network collapses word-wide are presented in several literatures. This problem is solved in literature. References [33]-[37], presents a sensitivity based approach has been proposed for optimal placement of UPFC to enhance voltage stability margin under contingencies. Reference [157], suggests a normal form analysis approach based on sensitivity indices is used for sitting power systems stabilizers (PSS) in power systems network. Reference [158], suggested a Trajectory Sensitivity Analysis (TSA) technique for the evaluation of the effect of TCSC placement on transient stability. The problem of low frequency power swings is a matter of concern for power engineers. The traditional solution to this problem is the use of power system stabilizers (PSSs). Different type of FACTS controllers also use for this problem. Such problems are solved in literature, a sensitivity based technique is used for placement of Static Synchronous Series Compensator (SSSC) in power system network in [159]. Sensitivity based screening technique for greatly reducing the computation involved in determining the optimal location of a Unified Power Flow Controller (UPFC) in a power system [160]. A sensitivity analysis and evolution programming technique has been proposed for placement of UPFC in a power system in [161]. In last two decades, full utilization of transmission among utilities for economic transfers has made the problem associated with voltage instability or voltage collapse a pressing issue. Numerous articles have been published around the world to discuss and find ways to tackle this pressing problem. Countries like Japan, France, Canada, and the United State have reported cases of voltage collapse with losses in millions of dollars. To prevent such instances to occur, system operators are looking for tools that can enhance their understanding of where the system is operating with respect to the point of collapse. Such problems are solved in [162], a sensitivity based technique used for determine the minimum amount of shunt reactive power (VAr) support which indirectly maximizes the real power transfer before voltage collapse is encountered. Sensitivity information that identifies weak buses is also available for locating effective VAr injection sites. A sensitivity based technique is used for determine optimal placement of Static Synchronous Compensator (STATCOM) and Unified Power Flow Controllers (UPFC) to enhancement of Dynamic Available Transfer Capability (ATC) under different contingencies in New England System [163]. A sensitivity factor based approach has been used in [164] for the optimal placement of the TCSC to minimize the congestion cost. In [165], a second-order sensitivity analysis technique used for optimal location of SVC and TCSC in power system. An eigen-value sensitivity based approach has been used for location and control- ler design of TCSC to enhance damping power system oscillations [166]. In [167], a new sensitivity factor, called System Loading Distribution Factor is used for determine the optimal location of UPFC in power system. A residues factor method has been used for determination of optimal location of the TCSC device to damp out the inter-area mode of oscillations [168]. In [169], a residues method based on sensitivity analysis technique is used for determine optimal location of the SVC to enhance the damping power system oscillations. A new approach based on sensitivity indices has been used for the optimal placement of various types of FACTS controllers such as TCSC, TCPAR and SVC in order to minimize total system reactive power loss and hence maximizing the static voltage stability in [201]. Magaji and Mustafa et al. [43] has been suggested a residue factor approach for optimal location of FACTS devices for damping oscillations of power systems. An opening of unused potentials of transmission system due to environmental, right-of-way and cost problems is a major concern of power transmission network expansion planners and policy makers. Flexible AC Transmission Systems (FACTS) controllers provide new control facilities, both in steady state power flow control and dynamic stability control. These problems are solved in literature, S. N. Singh and I. Erlich et al. [53], proposed for locating UPFC for enhancing power System loadability.

\subsection{Optimization Based Techniques}

This section reviews the optimal placement of FACTS controllers based on various optimization techniques such as a linear and quadratic programming, non-linear optimization programming, integer and mixed integer optimization programming, and dynamic optimization programming.

\subsubsection{Non-Linear Optimization Programming (NLP) Techniques}

When the objective function and the constraints are nonlinear, it forms non-linear programming (NLP). The difference between NLP and Linear Programming (LP) is analogous to the difference between a set of solving non-linear equations and a set of solving linear equations. In most of the NLP methods, the approach is to start from an initial guess and to determine a descent direction in which objective function decreases in case of minimization problems [5].

The study of non-linear behavior near critical equilibrium points is of great importance in the study of power system dynamic behavior. Classical approaches to system dynamic analysis have provided reliable methods for designing controllers that rely on linear analysis techniques. Local linearization of the system model at stationary points of vector fields, however, may fail to provide complete characterization of system performance or result in incomplete system information, especially under heavy stress or near the onset of unstable behavior. Reference [38], suggests a non-linear optimization programming techniques for assessing the placement of FACTS controllers in power 
system to damp electro-mechanical oscillations. A nonlinear optimization programming techniques has been proposed for optimal network placement of SVC controller in [39] and a Benders Decomposition technique has been used for these solutions.

\subsubsection{Integer and Mixed -Integer Optimization Program- ming (IP \& MIP) Techniques}

Reference [40], a mixed integer linear optimization programming algorithm has been proposed for the optimal placement of TCPST in multi-machine power systems. A mixed integer optimization programming algorithm has been proposed for optimal placement of Thyristor Controlled Phase Shifter Transformers (TCPSTs) in large scale power system for active flow and generation limits, and phase shifter constraints in [41]. Recently, several networks blackouts have been related to voltage collapse. This phenomenon tends to occur from lack of reactive power supports in heavily stressed conditions, which are usually triggered by system faults. Therefore, the voltage collapse problem is closely related to a reactive power planning problem including contingency analyses, where suitable conditions of reactive power reserves are analyzed for secure operations of power systems. A mixed integer optimization programming algorithm has been proposed for solved this problems for allocation of FACTS controllers in power system for security enhancement against voltage collapse and corrective controls, where the control effects by the devices to be installed are evaluated together with the other controls such as load shedding in contingencies to compute an optimal VAR planning [42].The deregulated power system has a basic challenge to provide network capable of delivering contracted power from any suppliers to any consumers over a large geographical area with continuously varying pattern of contractual agreements. Thus, the problem of power system security has obtained much attention in the deregulated power industry. In the present pace of power system restructuring, transmission systems are required to provide increased transfer capability and to accommodate much wider range of possible generation patterns. Environmental, right-of way and cost problems are major hurdles for power transmission network expansion. Such problems are solved in [170], a mixed integer non-linear optimization programming algorithm is used for determine the type, optimal number, optimal location of the TCSC for loadability enhancement in deregulated electricity markets. A mixed integer optimization programming algorithm has been used for optimal location of TCSC in a power system in [171].

\subsubsection{Dynamic Programming (DP) Techniques}

Oliveira et al. suggested a dynamic optimization programming algorithm for allocation of FACTS devices in hydrothermal systems in order to minimize the expected thermal generation costs and the investments on FACTS devices in a pre-specified time interval [44]. Chang and
Huang et al. showed that a hybrid optimization programming algorithm for optimal placement of SVC for voltage stability reinforcement [45]. In [46], a bellmann's optimality principle has been proposed for optimal sectionalizing switches allocation in distribution networks and also determines the optimal number of automatic sectionalizing switches devices. Lie and Deng et al. has addressed a decomposition coordination technique for optimal FACTS devices allocation in power system economic dispatch [47]. Zuwei and Lusan et al. presented review on the current status on the optimal placements of FACTS devices in power systems for enhances the damping of power system oscillations [48]. Orfanogianni and Bacher et al. suggested an optimization-based methodology is used for identify key locations of TCSC and UPFC include the nonlinear constraints of voltage limitation, zero megawatt active power exchange, voltage control, and reactive power exchange in the ac networks [173]. In [174], Curved Space Optimization (CSO) programming algorithm is used for allocation of SVC in a large power system.

\subsection{Artificial Intelligence (AI) Based Techniques}

This section reviews the optimal placement of FACTS controllers based on various Artificial Intelligence based techniques such as a Genetic Algorithm (GA), Expert System (ES), Artificial Neural Network (ANN), Tabu Search Optimization (TSO), Ant Colony Optimization (ACO) algorithm, Simulated Annealing (SA) approach, Particle Swarm Optimization (PSO) algorithm and Fuzzy Logic based approach.

\subsubsection{Genetic Algorithm (GA)}

A genetic algorithm has been addressed for optimal location of phase shifters in the French network to reduce the flows in heavily loaded lines, resulting in an increased loadability of the network and a reduced cost of production [49]. A genetic algorithm has been addressed for optimal location of multiple type FACTS controllers in a power system. The optimization are performed on three parameters; the location of the devices, their types and their values The system loadability is applied as measure of power system performance. Four different kinds of FACTS controllers are used as models for steady state studies: TCSC, TCPST, Thyristor Controlled Voltage Regulator (TCVR) and SVC in order to minimizing the overall system cost, which comprises of generation cost and investment cost of FACTS controllers [50]. Vijakumar and Kumudinidevi et al. presented a novel method for optimal location of FACTS controllers in a multi-machine power system. The location of FACTS controllers, their type and rated values are optimized simultaneously for the various FACTS controllers, TCSC and UPFC are considered in order to minimizing the overall system cost, which comprises of generation cost and investment cost of FACTS controllers [51]. One of the major problems that may associate with a stressed system is the voltage instability or collapse. Instability of the voltage 
can affect the performance of a power system. The main cause of voltage instability is insufficient reactive power supply. A stochastic searching algorithm called as genetic algorithm has been proposed for optimal placement of static VAR compensator for enhancing voltage stability in [52]. In [54], a genetic algorithm (GA) based method has been proposed for determine the optimal placement of FACTS controllers in power system with the consideration of economics and cost effectiveness. In [55], a genetic algorithm (GA) based approach has been proposed for the optimal choice and allocation of FACTS devices in deregulated electricity power market is to achieve the power system economic generation allocation and dispatch in deregulated electricity market. The locations of the FACTS controllers, their type and ratings are optimized simultaneously. The secure operation of power system has become an important and critical issue in today's large, complex, and load demand-increasing power systems. Security constraints such as thermal limits of transmission lines and bus voltage limits must be satisfied under any certain operating point. Commonly, power systems are planned and operated based on the N-I security criterion, which implies that the system should remain secure under all important first contingencies. One solution to cope with this problem is to design the system to meet N-I security criterion which is somewhat conservative and costly. An alternative solution to improve the security of power system. These problems are solved in literatures. Reference [56], genetic algorithm (GA) and particle swarm optimization (PSO) has been proposed for optimal location and parameter setting of UPFC for enhancing power system security under single contingencies. A new genetic algorithm (GA) based approach [57] has been addressed for selection of the optimal number and location of UPFC devices in deregulated electric power systems. In [58], a novel method such as a genetic algorithm has been presented for optimal location of FACTS controllers in a multi-machine power system. The location of FACTS controllers, their type and rated values are optimized simultaneously for the various FACTS controllers such as a TCSC and UPFC are considered. Reference [59], a genetic algorithm (GA) has been proposed for location and parameters setting of UPFC for congestion management in pool market model. The planning method such as a micro-genetic algorithm (MGA) has been addressed for optimal type selection and placement of a FACTS device for power system stabilizing purpose in a multimachine power system [60]. A heuristic approach using genetic algorithm has been addressed for optimal location of FACTS controllers in multi-machine power systems for enhancing the damping of power system oscillations in [61]-[64]. In [175], a non-traditional optimization technique, a Genetic Algorithm (GA) is conjunction with Fuzzy logic (FL) is used to optimize the various process parameters involved in introduction of FACTS devices such as a TCSC, Thyristor Controlled Phase Angle Regulator (TCPAR), SVC and UPFC in a power system. The various parameters taken into consideration were the location of the device, their type, and their rated value of the devices.
A multi-objective optimal power flow and genetic algorithms used to determine the optimal number and location of UPFC devices in an assigned power system network for maximizing system capabilities, social welfare and to satisfy contractual requirements in an open market power [176]. Power systems are operating closer to their stability and security limits. Recent blackouts happened in the USA or in Europe are some concrete consequences of that situation. This issue is also related to the growing technical and economic complexity of these large-scale dynamical systems. In practice, various disturbances such as short-circuits, transmission lines or device losses and load changes can strongly affect both power system stability and performance. Many power systems are facing with the problem of power system oscillations that occur due to the lack of damping torque at generators rotors. Lacking of damping torque may cause some critical power system blackouts in world such as the power system disturbance in WSCC-USA (August 10,1996) or the blackout in Sweden/Denmark (September 23,2003$)$. These problems are solved in [179], an energy approach has been used for the optimal location of FACTS controllers/sensors in large-scale power systems. Reference [180], a genetic algorithm (GA) has been proposed for optimal choice and allocation of FACTS devices such as UPFC, TCSC, TCPST, and SVC in deregulated electricity market.

\subsubsection{Tabu Search Algorithm (TS)}

A TS algorithm has been addressed for optimal placement of FACTS controllers such as TCSC, TCPST, UPFC, and SVC in multi-machine power systems [65]-[66]. Reference [172], a hybrid-meta heuristic method based on tabu search in conjunction with evolutionary particle swarm optimization technique has been proposed for optimal location of UPFC in power system.

\subsubsection{Simulated Annealing (SA) Algorithms}

Now a day the importance of power system design and operation with high efficiency, and maximum reliability and security has to be considered more than before. The difficulties in rights of path for transmission lines expansion lead to use the maximum capacity of the line and therefore, providing voltage stability even in normal conditions and related considerations become more difficult is presented in literatures. This problem is serious due to the fact that the generation units concern with active power generation rather than reactive power compensation in deregulated power systems. Such problem is solved in literatures. References [69], [70],a novel optimization based methodology such as a simulated annealing has been proposed for optimal location of FACTS devices such as TCSC and SVC in order to relive congestion in the transmission line while increasing static security margin and voltage profile of power system networks. In [177], the Goal Attainment (GA) method based on the SA approach is applied to solving general multi-objective VAR planning 
problems by assuming that the Decision Maker (DM) has goals for each of the objective functions. The VAR planning problem involves the determination of location and sizes of new compensators considering contingencies and voltage collapse problems in a power system.

\subsubsection{Particle Swarm Optimization (PSO) Algorithms}

In [71], a Particle Swarm Optimization (PSO) algorithm has been addressed for the solution of the Optimal Power Flow (OPF) using controllable FACTS controllers to enhance economic solution. Rashed et al. suggested a Genetic Algorithm (GA) and PSO techniques for optimal location and parameter setting of TCSC to improve the power transfer capability, reduce active power losses, improve stabilities of the power network, and decrease the cost of power production and to fulfill the other control requirements by controlling the power flow in multi-machine power system network [72]. A Trinary Particle Swarm Optimization Technique has been proposed for optimal switch placement in distribution systems for achieving high distribution reliability levels and con-currently minimizing capital costs can be considered as the main issues. A novel three state approaches has been proposed for inspired from the discrete version of a powerful heuristic algorithm, PSO is developed and presented to determine the optimal number and locations of two types of switches (sectionalizes and breakers) in radial power systems automation is an important issue from the reliability and economical point of view [73]. In [74]-[76], an Artificial Intelligence Based Techniques has been addressed for optimal placement of FACTS controllers in large scale power system. In [80], a Particle Swarm Optimization (PSO) technique has been addressed for optimal location of FACTS controllers such as TCSC, SVC, and UPFC considering system loadability and cost of installation.

\subsubsection{Ant Colony Optimization (ACO) Algorithms}

In [77], a methodology has been suggested for placement of sectionalizing switches in distribution networks in the presence of distributed generation sources for reliability improvement with consideration of economic aspects. In [78], an ACO algorithm has been addressed for the planning problem of electrical power distribution networks, stated as a mixed non-linear integer optimization problem, is solved using the Ant Colony System (ACS) algorithm. The ACS methodology is coupled with a conventional distribution system load flow algorithm and adapted to solve the primary distribution system planning problem. A Graph Search Algorithm has been addressed for optimal placement of fixed and switched capacitors on radial distribution systems to reduce power and energy losses, increases the available capacity of the feeders, and improves the feeder voltage profile [79].

\subsubsection{Fuzzy Logic (FL) Algorithms}

With increasing loading of existing power transmission systems, the problem of voltage stability and voltage collapse, has also become a major concern in power system planning and operation. Such problems are solved in literatures. References [81]-[82], A fuzzy logic based approach has been addressed for optimal placement and sizing of FACTS controllers in power systems. In [83], the theory of the normal forms of diffeomorphism algorithm has been addressed for the SVC allocation in multi-machine power system for power system voltage stability enhancement. Luna and Maldonado et al. has been addressed a new methodology is based on the evolutionary strategies algorithm known as Evolution Strategies (ES) for optimally locating FACTS controllers in a power system for maximizes the system loadability while keeping the power system operating within appropriate security limits [84]. A Gravitational Optimization (GO) algorithm has been addressed for allocation of SVC in a power system in [85]. Kalyani et al. [86] has been suggested an Evolutionary algorithm for optimal location of UPFC and sequential quadratic programming (SQP) to optimize the UPFC control settings. In [178], a knowledge and algorithm based approach is used to VAR planning in a transmission system. The VAR planning problem involves the determination of location and sizes of new compensators considering contingencies and voltage collapse problems in a power system. Fang and Ngan et al. [67] suggested an augmented Lagrange Multipliers approach for optimal location of UPFC in power systems to enhances the steady state performance and significantly increase the loadability of the system. Hao et al. [68] has been proposed an improved evolutionary programming technique for optimal location and parameters settings of UPFCs to maximize the system laudability subject to the transmission line capability and specified voltage level.

\section{Classification of Facts Controllers Coordination Techniques}

Coordination techniques of FACTS controllers are classified in three broad categories as sensitivity based methods, optimization based method, and artificial intelligence based techniques [3]-[5].

\subsection{Sensitivity Based Methods}

There are various sensitivity based methods such as a modal or eigen-value analysis, and index method. An eigen value analysis approach has been addressed for modeling and simulation of SVC and TCSC to study their limits on maximum loadability point in [11], [25]. A new methodology has been addressed for the solution of voltage stability when a contingency has occurred, using coordinated control of FACTS devices located in different areas of a power system. An analysis of the initial conditions to determine the voltage stability margins and a contingency analysis to determine the critical nodes and the voltage variations are conducted. The response is carried out by the coordination of multiple type FACTS controllers, which compensate the 
reactive power, improving the voltage stability margin of the critical modes [87]. In [88], an eigen value analysis approach has been addressed for the problem of the most effective selection of generating units to be equipped with excitation system stabilizers in multi-machine power systems which exhibit dynamic instability and poor damping of several inter machine modes of oscillations. A new coordination synthesis method using as an eigen value sensitivity analysis and linear programming has been addressed for simultaneous able to select the generators to which the PSS can be effectively applied and to synthesize the adequate transfer function of the PSSs for these generators [89]. Abdalle et al. suggested an eigen value analysis approach for a sequential procedure of coordinated stabilization in a multi-machine power system with arbitrary complexity of the system model [90]. In [91], an eigen value analysis technique has been addressed for designing PSS in multimachine power system. Xu and Zaid et al. presented a systematic method based on an eigen-value sensitivity analysis and linear programming for the tuning of multiple FACTS controllers in power system [92]. An eigen value sensitivity based analysis approach has been addressed for robust design of FACTS controllers in multi-machine power systems [93]. In [94], an eigen value sensitivity based analysis approach has been addressed for control coordination of series and shunt FACTS controllers in a multi-machine power system for series and shunt FACTS controllers considered are SVC, TCSC and SVC-TCSC combination. Chung et al. has been suggested a probabilistic eigen sensitivity based analysis for the selection of robust PSS location, parameters, and coordination for enhance the damping of multiple electro-mechanical modes in a multi-machine power systems over a large and prespecified set of operating conditions [95]. An eigen value sensitivity based analysis approach has been addressed for design and coordinate multiple stabilizers in order to enhance the electro-mechanical transient behaviour of power systems [96]. In [97], a modal analysis technique has been addressed for coordinated control of inter-area oscillation in the china southern power grid for parameter setting of selected power system stabilizers (PSS) and HVDC damping controllers. In [98], a Decentralized Modal Control (DMC) algorithm has been addressed for simultaneously selecting the power system stabilizers (PSS) parameters in multimachine power system in order to enhance damping of the power system oscillations. Torsional oscillations are excited as a result of interactions between the shaft systems of steam turbine-generator (T-G) sets and: (1) series capacitor compensated networks, and (2) power system controllers, e.g., excitation systems, governors and HVDC converter controllers. Torsional oscillations impose torsional torques on the shaft sections of T-G sets and as a result of the fatigue phenomenon reduce the life-time of the shaft sections. This problem solved in [99], an eigen value sensitivity based analysis approach has been addressed for coordinated control of SVC and PSSs in power system in order to enhance damping power system oscillations. In [100], an eigen-value sensitivity based analysis approach has been addressed for the evaluation and interpretation of eigen-value sensitivity, in the context of the analysis and control of oscillatory stability in multi-machine power systems. A modal analysis reduction technique has been suggested for multi-variable control design for damping inter-area oscillations of bulk power systems in order to raise precision and facilitate design procedures in [101]. The phenomenon of electro-mechanical oscillations in power systems is not new. However, it has evolved from being a local problem to becoming a global one. The interconnection of increasingly distant power systems and the trend to an intensive use of the transmission system explains this fact. Local oscillations (in range of 1-2 Hz) involve a few generators close to each other. In contrast, inter-area oscillations (in range of $0.2-1 \mathrm{~Hz}$ ) involve many generators spread out over the whole power system and are much more difficult to damp. The problem is solved in [102], a modal analysis based technique has been presented for design of robust controllers for damping inter-area oscillations application to the European power system. Gasca and Chow et al. has suggested a modal analysis based technique for the design of damping controllers in multi-machine power system or inter-area oscillations [103]. In [104], a residue based method has been presented for coordinated control of multiple FACTS controllers as well as to minimize the potential for adverse interaction between control loops. Ammari et al. [105] has addressed sensitivity and residues based techniques for robust solution for the interaction phenomena between dynamic loads and FACTS controllers for enhance damping of power system oscillations. In [106], a sensitivity based techniques such as a linear matrix inequalities techniques has been proposed for the design of robust PSS which places the system poles in acceptable region in the complex plane for a given set of operating and system conditions to enhance the damping of power system oscillations over the entire set of operating conditions. A frequency response technique has been used for coordinated design of under-excitation limiters and power system stabilizers (PSS) in power system for enhance the electromechanical damping of power system oscillations [107]. A root locus technique has been proposed for design of power system stabilizers (PSS) for damping out tie-line power oscillations in power system to enhance the damping of power system oscillations for different combinations of power system stabilizers parameters [108]. In [109], a projective control method has been addressed for coordinated control of two FACTS devices such as TCSC and Thyristor Controlled Phase Angle Regulator (TCPAR) for damping inter-area oscillations to enhance the power transfers and damping of power system oscillations. A problem of interest in the power industry is the mitigation of power system oscillations. These oscillations are related to the dynamics of system power transfer and often exhibit poor damping, with utilities increasing power exchange over a fixed network, the use of new and existing equipment in the transmission system for damping these oscillations is being considered in several literatures. The above problems are solved in lieratuters [110], [111], a projective control 
method has been addressed for coordinated control of TCSC and SVC for enhancing the dynamic performance of a power system. Tan and Wang et al. showed that an adaptive non-linear coordinated design technique for coordinated design of series and shunt FACTS controllers such as a Static Phase Shifter (SPS) and a Static VAR Compensators (SVC) controller in power systems environments for enhance the transient stability of the power system [112]. A non-linear technique has been proposed for robust nonlinear coordinated excitation and SVC control for power systems for enhance the transient stability of the power systems [113]. In [114], a new method has been proposed for the design of power system controllers aimed at damping out electro-mechanical oscillations used for applied to the design of both PSS for synchronous generators and supplementary signals associated to other damping sources. Milanovic and Hiskens et al. suggested a new method for tuning of SVC controllers in the presence of load parameters uncertainty to enhance the damping of electro-mechanical oscillations in power systems [115]. Voltage collapse problems in power systems have been a permanent concern for the industry, as several major blackouts throughout the world have been directly associated to this phenomenon, e. g., Belgium 1982, WSCC July 1996, etc. Many analysis methodologies have been proposed and are currently used for the study of this problem, as recently reported in several literatures These problems are solved in literature, Canizares and Faur et al. presented the steady-state models with controls of two FACTS controllers, namely SVC and TCSC, to study their effect on voltage collapse phenomena in power system to increase system loadability [116]. Lie et al. presented a linear optimal controller for the designed to implement multiple variable series compensators in transmission networks of inter-connected power system is utilized to damp inter-area oscillations and enhance power system damping [117]. An application of a normalized $H_{\infty}$ loop shaping techniques has been proposed for design and simplification of damping FACTS controllers in the linear matrix inequalities (LMI) framework in power system for enhance damping inter-area oscillation of power system [118]. In [119], a linear optimal controller has been addressed for the designed to implement multiple variable series compensators (VSCs) in transmission network of interconnected power system is utilized to damp inter-area oscillations and enhance power system damping during large disturbances. In [120], a new electricity trading arrangement has been addressed for the coordination of power flow control in a large power system, managing transmission constraints to meet the security standards against the back ground of this open market structure. An automatic control and coordination of power flow could be formulated as a multi-variable system design problem. The coordinated power flow control should address the following points such as elimination of interaction between FACTS controllers, ensuring system stability of the control process, security transmission system for both pre and post fault, and achieving optimal and economic power flow.

In [121], a new real and reactive power coordination method has been proposed for UPFC to improve the performance of the UPFC control. In [122], a new methodology has been proposed for transmission network voltage regulation through coordinated automatic control of reactive power. A new method has been suggested for the potential application of coordinated secondary voltage control by multiple FACTS voltage controllers in eliminating voltage violations in power system contingencies in order to achieve more efficient voltage regulation in a power system. The coordinated secondary voltage control is assigned to the SVCs and Static Compensators (STATCOM) in order to eliminate voltage violations in power system contingencies [123]. Fan et al. addressed a new coordinated control strategy for optimal coordinated Power Electronic Transformers (PET) and generator excitation control for power system to improve the system stability by a generator-PET unit [124]. In [125], a new multi-variable dynamic model and a control approach has been addressed for a Voltage Source Converter (VSC) based on adapting instantaneous real and reactive power components as the VSC dynamic variable. Use of this power component as the dynamic variables reduces the degree of non-linearities of the VSC model in comparison with the conventional VSC model that uses dq current components as variables. Furthermore, since wave forms of power components are independent of the selected qd coordinates, the proposed control is more robust to the conventionally un-modeled dynamics such as dynamic of the VSC phase locked loop system. A new methodology has been proposed for decentralized optimal power flow control for overlapping area in power systems for the enhancement of the system security [126]. Iravani et al. have been presented a theoretical back ground and the methodology of development of a software tool for off-line coordination of power system controllers in either a high frequency range $(5-55 \mathrm{~Hz})$ or a low frequency range $(0.1-2 \mathrm{~Hz})$ [127]. The controllers considered for coordination are voltage regulators, PSS, speed governors, main and auxiliary controllers of HVDC converters, and main and auxiliary controllers of SVC. A new methodology has been proposed for designing a coordinated controller for a synchronous generator excitation and SVC in power system is to extend the operational margin of stability, whilst satisfying control requirements by introducing an integrated multi-variable controller to control both the generator exciter and the firing angle of the thyristor controlled reactor of TCR-FC compensators [128]. In [181], an eigenvalue analysis technique is used for coordinated control of PSS and FACTS controllers to enhance damping of power system oscillations in multi-machine power system. A sensitivity based analysis approach is used to find out an intercoupling between a variation of set points of different FACTS devices and a volume of load shedding with a variation of active power flow in transmission lines [182]. In [191], an H-infinity optimization technique has been used for simultaneous tuning of TCSC controllers in power system for a wide range of operating conditions. Zhao and Jiang et al. suggested a $\mathrm{H}$-infinity optimization technique for simultaneous tuning of SVC controllers design to im- 
prove the damping power system [192]. Chaudhuri and Pal et al. suggested a H-infinity damping control design optimization technique based on the mixed sensitivity formulation in a linear matrix inequality (LMI) framework for robust damping control design for multiple swing modes damping in a typical power system model using global stabilizing signals [193]. A systematic procedure for the synthesis of a Supplementary Damping Controller (SDC) for Static Var Compensator (SVC) for a wide range of operating conditions is used for testing in multi-machine power systems to enhance the damping of the inter-area oscillations, providing robust stability and good performance characteristics both in frequency domain and time domain [194]. Yue and Shlueter et al. presented a multiple bifurcation phenomena for three kinds of $\mu$-synthesis robust controls are designed such as $\mu$-synthesis power system stabilizer (MPSS), $\mu$-synthesis SVC control (MSVC), and a mixed MPSS/MSVC control [195]. In [196], a bifurcation subsystem based methodology has been proposed for $\mu$ synthesis power system stabilizers design in a two-area power system. The secure operation of power systems requires the application of robust controllers, such as Power System Stabilizers (PSS), to provide sufficient damping at all credible operating conditions. Recently, many researchers have investigated the use of robust control techniques including $\mathrm{H}$-infinity optimization and $\mu$-synthesis techniques for developing advanced and automated procedures for power system damping controller design. A several control design techniques [197] such as the classical phase compensation approach, the $\mu$-synthesis, and a linear matrix inequality technique has been used for coordinate two PSS to stabilize a 5-machine equivalent of the South/ Southeast Brazilian power system. In [198], a Prony methods based on Prony signal analysis and incorporates both local and inter-area electro-mechanical oscillatory modes along with root locus and sequential decentralized control techniques has been used for PSSs design in multi-machine power systems. A design method that explicitly considers both the coordination and the robustness issues has been proposed for coordinated design of power system stabilizers and supplementary control of FACTS devices to enhance the robustness of the control scheme for drastic changes in the operating condition [199]. This method is based on the formulation and solution of an augmented Riccati equation. In [200], a projective control principle based on eigenvalue analysis has been presented for coordinated control design of supplementary damping controller of HVDC and SVC in power system to enhance the damping of power system oscillations.

\subsection{Optimization Based Techniques}

This section reviews the coordination of FACTS controllers based on various optimization techniques such as a linear and quadratic programming, non-linear optimization programming, integer and mixed integer optimization programming, and dynamic optimization programming.

\subsubsection{Non-linear Optimization Programming Techniques}

In [129], a new method based on the optimization method is called non-linear optimization programming technique has been addressed for tuning the parameters of the PSS for enhancing small-signal stability. A non-linear optimization programming techniques has been addressed for simultaneous coordinated tuning of PSS and FACTS controllers for damping power system oscillations in multimachine power systems [130]. Lei et al. suggested a sequential quadratic programming algorithm for optimization and coordination of FACTS device stabilizers (FDS) and power system stabilizers (PSS) in a multi-machine power system to improve system dynamic performance [131]. Electro-mechanical oscillations in power systems are a problem that has been challenging engineers for decades. These oscillations may be very poorly damped in some cases, resulting in mechanical fatigue at the machines and unacceptable power variations across important transmission lines. For this reason, the use of controllers to provide better damping for these oscillations is of utmost importance. A non-linear programming based algorithm has been proposed for the design of power system damping controllers for damp electro-mechanical oscillations in power systems [132]. A non-linear programming based algorithm has been proposed for the design of simultaneous coordinated tuning of PSS and FACTS controllers for damping power system oscillations in multi-machine power systems [133]. Simoes et al. presented a non-linear optimization technique is used to coordinated control of Power Oscillation Damping (POD) controllers implemented in the two TCSC of the Brazilian North-South (NS) inter-connection, in the year 1999, were solely intended to damp the low-frequency NS oscillation mode [184].

\subsubsection{Linear Optimization Programming Techniques}

In [134], a systematic optimization method has been addressed for the design of a linear optimal power system stabilizer, under the conditions of pre-specified closed loop dominant eigen-value locations and feedback gain limit constraints. A linear programming algorithm has been used for simultaneous coordination of PSS and FACTS device stabilizers in a multi-machine power system for enhancing dynamic performance of the rotor modes of oscillations [135]. As one typical power system instability phenomena, voltage collapse has received substantial research and many indices and approaches for predicting voltage collapse have been proposed over the last decade. However, for practical purposes, it is not sufficient to merely understand and analyze voltage collapse mechanisms, it is essential to seek for effective and economically justified solutions to the problem. Feng et al. suggested a comprehensive approach for determination of preventive and corrective control strategies to contain voltage collapse in stressed power systems [136]. An immune-based algorithm has been addressed for optimal coordination of local physically based controllers in order to presence or retain mid 
and long term voltage stability [137]. A design approach such as non-linear constrained optimization has been proposed for robust design and coordination of multiple damping controllers in multi-machine power system [138]. In [139], a new technique has been suggested for coordinated local and centralized control in distribution management systems. Glanzmann and Anderson et al. suggested a supervisory controller based on optimal power flow (OPF) with multiple objective for derived in order to avoid congestion provide secure transmission and minimize active power losses. The contribution of SVC, TCSC and TCPST in coordinated control and achieved improvements is presented [140]. Low frequency oscillations are a quite common problem in most interconnected power systems today. These oscillations are due to dynamic interactions between the various generators of a system, through its transmission network, and are usually associated to the presence of automatic voltage regulators (AVRs) with high gain in the generators and long transmission lines establishing weak connections between distinct areas of a system. Due to this phenomenon, limits often have to be placed on the maximum amount of power that can be transferred over these strategic lines, to ensure a safe operation of the system. Therefore, equipment and procedures to enhance the damping of these oscillations become mandatory for the system operation, in order to allow a better use of the existent transmission network. These problems are improved, in [141][142], a new methodology has been proposed for the coordinated design of robust decentralized power system damping controllers to provide controllers capable of fulfilling various practical requirements of the oscillations damping problem, which could not be simultaneously satisfied by the majority of the robust approaches. Today's power grids are driven closer to their transfer capacities due to the increased consumption and power transfers, endangering the security of the system. On the other hand, FACTS devices are a power ful technology that can solve many outstanding problems in power systems. They provide the opportunity to influence power flows and voltages andf therefore is able to enhance the system security, e. g., by improving the voltage profile or increasing the transfer capacity of the system without the need of new lines. In [143], a new methodology has been proposed for coordinated control of FACTS devices in power system for security enhancement. In [183], an optimization technique is used to tuning of power system stabilizers in power systems. Small disturbance stability, particularly in the context of positive damping of electro-mechanical modes or oscillations among the interconnected synchronous generator in power systems, constitutes one of the essential criteria for secure system operation. Power system stabilizers (PSSs) together with their coordination have been developed for enhancing system stability. However, the use of PSSs only may not be, in some cases, effective in providing sufficient damping for inter-area oscillations, particularly with increasing transmission line loading over long distances. Drawing on the availability of FACTS devices at present, which have been developed primarily for active- and/or reactive power flow and voltage control functions in the transmission system, more effective measures have been proposed for improving system damping. Nguyen, and Gianto et al. [203]-[204] has been proposed a optimization based technique for control coordination of PSSs and FACTS controllers for Optimal oscillations damping in multi-machine power system. Damping of power system oscillations between interconnected areas is very important for the system secure operation. Power system stabilizers (PSS) and FACTS devices are used to enhance system stability. In large power systems, using only conventional PSS may not provide sufficient damping for inter-area oscillations. In these cases, FACTS power oscillation damping controllers are effective solutions. But uncoordinated local control of FACTS devices and PSSs may cause destabilizing interactions. Najafi and Kazemi et al. [206] suggested an optimization based technique for coordination of PSSs and FACTS damping controllers in large power systems for dynamic stability improvement. In [207], an approach has been presented for coordinated wide area control of FACTS controllers for congestion management. In [210], an optimization based approach has been suggested for power system optimization and coordination of FACTS controllers to significant transient stability improvement and effective power oscillation damping.

\subsection{Artificial Intelligence (AI) Based Techniques}

This section reviews the coordinated control of FACTS controllers based on various Artificial Intelligence based techniques such as genetic algorithm (GA), expert system (ES), artificial neural network (ANN), tabu search optimization, ant colony optimization algorithm, simulated annealing approach, particle swarm optimization algorithm, and fuzzy logic based approach.

\subsubsection{Genetic Algorithm (GA)}

GA is a global search technique based on mechanics of natural selection and genetics. It is a general purpose optimization algorithm that is distinguished from conventional optimization techniques by the use of concepts of population genetics to guide the optimization search. Instead of point to point search, GA searches from population to population. The advantages of GA over traditional techniques is that it needs only rough information of the objective function and places no restriction such as differentiability and convexity on the objective function, the method works with a set of solutions from one generation to next, and not a single solution, thus making it less likely to converge on local minima, and the solutions developed are randomly based on the probability rate of the genetic operators such as mutation and crossover; the initial solutions thus would not dictate the search direction of GA.A major disadvantage of GA method is that it requires tremendously high time.

In [144], a genetic algorithm based on the method of inequalities has been addressed for the coordinated synthesis PSS parameters in a multi-machine power system in 
order to enhance overall system small signal stability. In [145], GA is applied for the simultaneously tuning multiple power system damping controllers in power system over a pre-specified set of operating conditions. Congestion in the transmission lines is one of the technical problems that appear particularly in the deregulated environment. These are two types of congestion management methodologies to relieve it. One is non-cost free methods and another is cost free methods, among these, later method relives the congestion technically whereas the former is related with the economics. Reddy et al. presented the congestion management is relieved using cost free methods for using FACTS devices, congestion can be reduced without disturbing the economic matters [146]. TCSC and UPFC are two mainly emerging FACTS devices and they are used to reduce the congestion. In congestion management, the objective function is non-linear hence in solving this function Genetic Algorithm (GA) technique is used to obtain the global optimal solution. A systematic procedure has been addressed for modeling and simulation of a power system installed with Power System Stabilizers (PSS) and FACTS based controllers to avoid adverse interaction, PSS and FACTS based controller are simultaneously designed employing genetic algorithms (GA) [147]. In [185], a robust controller design technique based on genetic algorithm is used to simultaneously tune PSS for multiple operating conditions. In [186], a genetic algorithm is used for the simultaneous stabilization of multi-machine power systems over a wide range of operating conditions via single setting power system stabilizers. Sebaa and Boudour et al. [209] has been suggested a genetic algorithm for coordinated design of PSSs and SVC-based controllers in power system to enhance power system dynamic stability.

\subsubsection{Tabu Search Algorithms}

Tabu search (TS) algorithm was originally proposed as an optimization tool by Glover in 1977 [5]. It is a conceptually simple and an elegant iterative technique for finding good solutions to optimization problems. In general terms, TS is characterized by its ability to escape local optima by using a short term memory of recent solutions called the tabu list. Moreover, tabu search permits back tracking to previous solutions by using the aspiration criterion [5]. Reference [148], a tabu search algorithm has been addressed for robust tuning of power system stabilizers in multi-machine power systems, operating at different loading conditions.

In [187], robust frequency stabilization is used for coordinated control of Superconducting Magnetic Energy Storage (SMES) and Static Synchronous Series Compensator (SSSC) to enhance the robustness of frequency stabilizers against uncertainties.

\subsubsection{Simulated Annealing Algorithms}

In the last few years, Simulated Annealing (SA) algorithm appeared as a promising heuristic algorithm for han- dling the combinatorial optimization problems [74]. It has been theoretically proved that the SA algorithm converges to the optimum solution. The SA algorithm is robust i.e. the final solution quality does not strongly depend on the choice of the initial solution. Therefore, the algorithm can be used to improve the solution of other methods. Another strong feature of SA algorithm is that a complicated mathematical model is not needed and the constraints can be easily incorporated unlike the gradient descent technique, SA is a derivative free optimization algorithm and no sensitivity analysis is required to evaluate the objective function. This feature simplifies the constraints imposed on the objective function considered.

In [149], a simulated annealing based algorithm has been addressed for PSS and FACTS based stabilizers tuning in power systems. The design problem of PSS and FACTS based stabilizes is formulated as an optimization problem. An eigen value based objective function is used to increase the system damping. Then SA algorithm is employed to search for optimal stabilizer parameters. Different control schemes have been proposed in and tested on a weakly connected power system with different disturbances loading conditions and parameter variations.

\subsubsection{Particle Swarm Optimization (PSO) Algorithms}

Recently, Particle Swarm Optimization (PSO) algorithm appeared as a promising algorithm for handling the optimization problems [74]. PSO shares many similarities with GA optimization technique, like initialization of population of random solutions and search for the optimal by updating generations. However, unlike GA, PSO has no evolution operators such as crossover and mutation. One of the most promising advantages of PSO over GA is its algorithmic simplicity as it uses a few parameters and easy to implement. In PSO, the potential solutions, called particle, fly through the problem space by following the current optimum particles.

References [150], [190], a PSO algorithm has been suggested for coordinated design of a TCSC controller and PSS in power systems for enhancing the power system stability. The design problem of PSS and TCSC based controllers is formulated as a time domain based optimization problem. PSO algorithm is employed to search for optimal controller parameters, by minimizing the time domain based objective function, in which the deviation in the oscillatory rotor speed of the generator is involved. Controllers are designed independently first and then in a coordinated manner for individual and coordinated application. The proposed controllers are tested on a weakly connected power system. Low frequency oscillations are observed when large power systems are interconnected by relatively weak tie lines. These oscillations may sustain and glow to cause system separation if no adequate damping is available. Power System Stabilizers (PSS) are now routinely used in the industry to damp out oscillations. An appropriate selection of PSS parameters results in satisfactory performance during system disturbances. The problem of PSS parame- 
ters tuning is a complex exercise. A number of conventional techniques have been reported in the several literatures pertaining to design problems of conventional power system stabilizers namely; the eigenvalue assignment, mathematical programming, gradient procedure for optimization and also the modern control theory. Unfortunately, the conventional techniques are time consuming as they are iterative and require heavy computation burden and slow convergence. These problems are minimized in literature, Panda and Aril et al. [205] suggested a PSO technique for robust coordinated design of PSSs in multi-machine power system to enhance the stability performance of the power system.

\subsubsection{Artificial Neural Network (ANN) Optimization Al- gorithms}

The starting point of ANN was the training algorithm proposed by Hebb in 1949, which demonstrated how a network of neurons could exhibit learning behaviour. ANN are mainly categorized by their architecture (number of layers), topology (connectivity pattern, feed forward etc.) and learning regime. Most of the applications of an ANN in the power systems use multi-layer feed forward network. The main advantages of ANN are it is fast possesses learning ability, adapts to the data, robust and appropriate for non-linear modeling. These advantages suggest the use of ANN for voltage security monitoring and control through the neural network training is generally computationally expensive, it takes negligible time to evaluate voltage stability once the network has been trained. Despite the advantages, some disadvantages of the ANN are large dimensionality selection of the optimum configuration, the choice of training methodology, the black-box representation of ANN they lack explanation capabilities and so decisions are not audible, and the fact that results are always generated even if the input data are unreasonable.

Etingov et al. suggested an emergency control system based on the ANN technique for finding a coordinated control system action (load shedding, generation tripping) to prevent the violation of power system stability. [151]. Nguyen, and Gianto et al. [202] has been proposed a neural networks approach for online control coordination which leads to adaptive power system stabilizers (PSSs) and/or supplementary damping controllers of Flexible AC Transmission System (FACTSs) devices for enhancing the stability of the electro-mechanical modes in a multi-machine power system.

\subsubsection{Fuzzy logic (FL) Algorithms}

Fuzzy logic was developed by Zadeh in 1964 to address uncertainty and imprecision which widely exist in the engineering problems and it was first introduced in 1979 for solving power system problems. Fuzzy set theory can be considered as a generation of the classical set theory. In classical set theory an element of the universe either belongs to or does not belong to the set. Thus the degree of associations of an element is crisp. In a fuzzy set theory the association of an element can be continuously varying. Mathematically, a fuzzy set is a mapping (known as membership function) from the universe of discourse to the closed interval $[0,1]$. The membership function is usually designed by taking into consideration the requirement and constraints of the problem. Fuzzy logic implements human experiences and preferences via membership functions and fuzzy rules. Due to the use of fuzzy variables, the system can be made understandable to a non-expert operator. In this way, fuzzy logic can be used as a general methodology to incorporate knowledge, heuristics or theory into controllers and decision makers. The advantages of fuzzy set theory are more accurately represents the operational constraints of power systems, and fuzzified constraints are softer than traditional constraints.

The problem of poorly damped, low frequency oscillations, associated with the generator rotor swings has been a matter of concern to power engineers for along time. Damping of electro-mechanical oscillations between interconnected synchronous generators is necessary for secure system operation. These problem is improved, in [152], a fuzzy set theory based algorithms has been suggested for coordinate stabilizers so as to increase the operational dynamic stability margin of power system for TCSC and UPFC in power system environments. A new fuzzy algorithm has been addressed for enhancing the performance of output feedback controllers [153]. This fuzzy system has a simple structure and acts as a non-linear function so that the gain of the controller is not constant but changes according to the error value. A hybrid fuzzy logic algorithm has been proposed for the coordination of FACTS controllers in power system. The coordination method is well suitable to series connected FACTS devices like TCSC, SSSC in damping multi-modal oscillations in multi-machine power systems [154]. In [155], a fuzzy logic based algorithms has been proposed for power system governing multiple FACTS devices using fuzzy reasoning in order to meet the requirements for power flow. A fuzzy logic coordination algorithm has been proposed to deals with the control of the series FACTS devices for the coordination between their transient stability controller and Power Oscillation Damping (POD) controller in multi-machine power system environments [156]. A fuzzy logic based method is used for decentralized coordination of FACTS devices for power system stability enhancement in [188]. A fuzzy logic based method has been used for coordinated control of TCSC and UPFC in power systems to increase the operational dynamic stability margin of power system [189]. In [208], a relative gain array (RGA) theory has been proposed for interaction analysis and coordination control between SSSC and SVC. Electric utility industry is undergoing rapid changes word -wide as seen from structural reformation of the electricity market in many leading countries. Following the trend of deregulating the electric power industry, a demand for flexible power load flow control is becoming a technical need feasibly achievable by the innovative power electronic technology. In terms of 
load flow control in the transmission network, operator cannot do much traditionally except turning on and off the circuits at their terminals. The network is slow in response to contingency cases and is difficult to cope with system load flow control required in terms of speed and versatility. Such problems are solved in literature. Reference [211], a load flow control technique has been proposed for coordinated control of FACTS controllers in power system for enhancing steady dynamic performance of power systems during normal and abnormal operation conditions. Qing and Zengzing et al. [212] has been suggested a fuzzy immune co-evolutionary algorithm for coordinated control of SSSC and static compensator (STATCOM) in power system.

\section{Summary of the Paper}

The following tables give summary of the paper as:

\subsection{Methods/Techniques for Placement of FACTS Controllers}

\subsubsection{Methods/Techniques Point of View}

Table 1. Methods/Techniques point of view

\begin{tabular}{c|c|c}
\hline Methods/Techniques & $\begin{array}{c}\text { Total No. of Litera- } \\
\text { tures Reviews out } \\
\text { of 106 Literatures }\end{array}$ & $\begin{array}{c}\text { \% of Literatures } \\
\text { Reviews out of } \\
\text { 106 Literatures }\end{array}$ \\
\hline Sensitivity based methods & 48 & 45.28 \\
\hline Optimization based methods & 14 & 13.20 \\
\hline AI-based techniques & 44 & 41.51 \\
\hline
\end{tabular}

\subsubsection{Operating Parameters Point of View}

Table 2. Operating Parameters point of view

\begin{tabular}{c|c|c}
\hline $\begin{array}{c}\text { Operating Parameters of } \\
\text { Power systems }\end{array}$ & $\begin{array}{c}\text { Total No. of Litera- } \\
\text { tures Reviews out } \\
\text { of 106 Literatures }\end{array}$ & $\begin{array}{c}\text { \% of Literatures } \\
\text { Reviews out of } \\
\text { 106 Literatures }\end{array}$ \\
\hline $\begin{array}{c}\text { Damping of power } \\
\text { system oscillations }\end{array}$ & 16 & 15.09 \\
\hline Voltage Profile & 20 & 18.87 \\
\hline $\begin{array}{c}\text { Security of the } \\
\text { power system }\end{array}$ & 02 & 1.89 \\
\hline $\begin{array}{c}\text { Small signal stability, } \\
\text { transient stability }\end{array}$ & 06 & 1.89 \\
\hline $\begin{array}{c}\text { Power transfer capability } \\
\text { through the lines }\end{array}$ & 02 & 11.32 \\
\hline $\begin{array}{c}\text { Dynamic performances of } \\
\text { power systems }\end{array}$ & 12 & 43.39 \\
\hline $\begin{array}{c}\text { The loadability of the power } \\
\text { system network }\end{array}$ & 46 & 59 \\
\hline $\begin{array}{c}\text { Others parameters } \\
\text { point of view }\end{array}$ & 02 & \\
\hline
\end{tabular}

From above tables it is concluded that the $45.28 \%$ of total literatures are reviews based on sensitivity methods, $13.20 \%$ of total literatures are reviews based on optimization programming and the $41.51 \%$ of total literatures are reviews on AI based techniques regarding with placement of FACTS controllers in multi-machine power systems. It is also concludes that the $15.09 \%$ of total literatures are reviews carryout from damping of power system oscillations, $18.87 \%$ of total literatures are reviews carryout from voltage stability, $1.89 \%$ of total literatures are reviews carryout from security of power system, $5.66 \%$ of total literatures are reviews carryout from small signal/transient/ dynamic stability, $1.89 \%$ of total literatures are reviews carryout from power transfer capability through the lines, $1.89 \%$ of total literatures are reviews carryout from dynamic performance of power system, $11.32 \%$ of total literatures are reviews carryout from the loadability of power system, and $43.39 \%$ of total literatures are reviews carryout from other parameters viewpoints.

\subsection{Methods/Techniques for Coordination of FACTS Controllers}

\subsubsection{Methods/Techniques Point of View}

Table 3. Methods/Techniques point of view

\begin{tabular}{c|c|c}
\hline Methods/Techniques & $\begin{array}{c}\text { Total No. of Litera- } \\
\text { tures Reviews out of } \\
\text { 101 Literatures }\end{array}$ & $\begin{array}{c}\text { \% of Literatures } \\
\text { Reviews out of } \\
\text { 101 Literatures }\end{array}$ \\
\hline Sensitivity based methods & 56 & 55.45 \\
\hline Optimization based methods & 22 & 21.78 \\
\hline AI-based techniques & 23 & 22.77 \\
\hline
\end{tabular}

\subsubsection{Operating Parameters Point of View}

Table 4. Operating Parameters point of view

\begin{tabular}{c|c|c}
\hline $\begin{array}{c}\text { Operating Parameters of } \\
\text { Power systems }\end{array}$ & $\begin{array}{c}\text { Total No. of Litera- } \\
\text { tures Reviews out } \\
\text { of 101 Literatures }\end{array}$ & $\begin{array}{c}\text { \% of Literatures } \\
\text { Reviews out of } \\
\text { 101 Literatures }\end{array}$ \\
\hline $\begin{array}{c}\text { Damping of power system } \\
\text { oscillations }\end{array}$ & 34 & 33.66 \\
\hline Voltage Profile & 05 & 4.95 \\
\hline $\begin{array}{c}\text { Security of the } \\
\text { power system }\end{array}$ & 04 & 3.96 \\
\hline $\begin{array}{c}\text { Small signal stability, } \\
\text { transient stability }\end{array}$ & 13 & 12.87 \\
\hline $\begin{array}{c}\text { Power transfer capability } \\
\text { through the lines }\end{array}$ & 02 & 8.91 \\
\hline $\begin{array}{c}\text { Dynamic performances of } \\
\text { power systems }\end{array}$ & 02 & 1.98 \\
\hline $\begin{array}{c}\text { The loadability of the } \\
\text { power system network }\end{array}$ & 32 & 31.68 \\
\hline $\begin{array}{c}\text { Others parameters } \\
\text { point of view }\end{array}$ & 09 & \\
\hline
\end{tabular}

From above tables it is concluded that the $55.45 \%$ of total literatures are reviews based on sensitivity methods, $21.78 \%$ of total literatures are reviews based on optimization programming, and the $22.77 \%$ of total literatures are reviews on AI based techniques regarding with coordination of FACTS controllers in multi-machine power systems. It is also concludes that the $33.66 \%$ of total literatures are reviews carryout from damping of power system oscillations, $4.95 \%$ of total literatures are reviews carryout from voltage stability, $3.96 \%$ of total literatures are reviews carryout from security of power system, $12.87 \%$ of total literatures are reviews carryout from small signal/transient/ 
dynamic stability, $1.98 \%$ of total literatures are reviews carryout from power transfer capability through the lines, $8.91 \%$ of total literatures are reviews carryout from dynamic performance of power system, $1.98 \%$ of total literatures are reviews carryout from the loadability of power system, and $31.68 \%$ of total literatures are reviews carryout from other parameters viewpoints.

Finally it is concluded that the maximum research work carryout from damping of power system oscillations and voltage stability point of view regarding with placement and coordination of FACTS controllers in multi-machine power systems.

\section{Conclusion}

In this paper an attempt has been made to reviews, various AI based optimization methods used for the placement and coordination of FACTS controllers. Even through, excellent advancements have been made in classical methods i. e. sensitivity based method; they suffer with the following disadvantages: In most cases, mathematical formulations have to be simplified to get the solutions because of the extremely limited capability to solve real-word large-scale power system problems. They are weak in handling qualitative constraints. They have poor convergence, may get stuck at local optimum, they can find only a single optimized solution in a single simulation run, they become too slow if number of variables are large and they are computationally expensive for solution of a large power system.

Whereas, the major advantage of the AI based optimization methods is that they are relatively versatile for handling various qualitative constraints. AI methods can find multiple optimal solutions in single simulation run. So they are quite suitable in solving multi-objective optimization problems for placement and coordination of FACTS controllers in multi-machine power system. In most cases, they can find the global optimum solution. The main advantages of ANN are: possesses learning ability, fast, appropriate for non-linear modeling, etc. whereas, large dimensionality and the choice of training methodology are some disadvantages of ANN. The advantages of Fuzzy method are: Accurately represents the operational constraints and fuzzified constraints are softer than traditional constraints. The advantages of GA methods are: It only uses the values of the objective function and less likely to get trapped at a local optimum. Higher computational time is its disadvantage. The advantages of EP are adaptability to change, ability to generate good enough solutions and rapid convergence. ACO and PSO are the latest entry in the field of optimization. The main advantages of ACO are positive feedback for recovery of good solutions, distributed computation, which avoids premature convergence. It has been mainly used in finding the shortest route in transmission network, short-term generation scheduling and optimal unit commitment. PSO can be used to solve complex optimization problems, which are non-linear, non-differentiable and multi-model. The main merits of PSO are its fast convergence speed and it can be realized simply for less parameters need adjusting. PSO has been mainly used to solve Bi-objective generation scheduling, optimal reactive power dispatch and to minimize total cost of power generation. The applications of ACO and PSO for placement and coordination of FACTS controllers in multi-machine power system.

This paper has also addressed a survey of several technical literature concerned with various techniques/methods for placement and coordination of multiple FACTS controllers in multi-machine power system environments to show that the achieve significant improvements in operating parameters of the power systems such as small signal stability, transient stability, damping of power system oscillations, security of the power system, less active power loss, voltage profile, congestion management, quality of the power system, efficiency of power system operations, power transfer capability through the lines, dynamic performances of power systems, and the loadability of the power system network also increased. This review also shows that installing multiple controllers on the system may not improve the dynamic performance due to undesirable interactions. The tuning of one controller may affect other controllers and thus lead to unstable conditions. These issues should be taken into consideration when designing systems with multiple controllers. The implementation of a coordinated controller tuning procedure to avoid undesirable interactions in power systems, and thus improve overall dynamic performance is under this review.

Authors strongly believe that this survey article will be very much useful to the researchers for finding out the relevant references as well as the previous work done in the field of placement and coordination of FACTS Controllers for the various methods/techniques for coordination and placement of FACTS controllers in multi-machine power systems. So that further research work can be carried out.

\section{Acknowledgements}

The authors would like to thanks Dr. S. C. Srivastava, Indian Institute of Technology, Kanpur, for discussions regarding placement and coordination techniques for FACTS controllers in multi-machine power systems environments.

\section{References}

[1] M. J. Gibbard, D. J. Vowles, and P. Pourbeik, "Interactions between and Effectiveness of Power Systems Stabilizers and FACTS controllers in Multi-Machine Systems," IEEE Trans. on Power Systems, Vol.15, No.2, pp.748-755, May, 2000.

[2] Kundur P., "Inter-area Oscillations in Power System," IEEE Power Engineering Society, pp.13-16, Oct., 1994.

[3] W. Zhang, F. L., and Leon M. Tolbert, "Optimal Allocation of Shunt Dynamic VAR Source SVC and STATCOM: A Survey," IEEE Trans on Power systems, Vol.22, No.3, Oct., 2007. 
[4] H. N. Ng, M. M. A. Salama, and A. Y. Chikhani, "Classification of Capacitor Allocation Techniques," IEEE Trans. on Power Delivery, Vol.15, No.1, Jan., 2000.

[5] R. C. Bansal, "Optimization Methods for Electric Power Systems: An Overview," International Journal of Emerging Electric Power Systems, Vol.2, issues-1, 2005.

[6] R. J. Fleming, M. A. Mohan, and K. Parvatisam, "Selection of Parameters of Stabilizers in Multi-machine Power System," IEEE Trans on Power Apparatus and Systems, Vol.PAS-100, No.5, May, 1981.

[7] Yuan-Yih Hsu, and Chern-Linchen, "Identification of Optimum Location for Stabilizers Application Using Participation Factors," IEE Proc., Vol.134, Pt.C. No.3, May, 1987.

[8] Jin Lu Hsiao-Dong Chiang and James S. Thorp, "Identification of Optimum sites for Power System Stabilizers Applications," IEEE Trans on Power Systems, Vol.5, No.4, Nov., 1990.

[9] L. A. S. Pilotto, W. W. Ping, A. R. Carvalino, A. Wey, W. F. Long, F. L. Alvarado, and A. Edris, " Determination of Needed FACTS Controllers that Increase Asset Utilization of Power Systems," IEEE Trans on Power Delivery, Vol.12, No.1, Jan., 1997.

[10] Y. Mansour, W. Xu. F. Alvarado, and C. Rinzin, "SVC Placement Using Critical Modes of Voltage Stability," IEEE Trans. on Power Systems, Vol.9, pp. 757-762, May, 1994.

[11] A. Kazemi, and B. Badrzadeh, "Modeling and Simulation of SVC and TCSC to Study Their Limits on Maximum Loadalibility Point," Electrical Power \& Energy Systems, Vol.26, pp.619-626, 2004.

[12] Cigre Working Group, "Modeling of Static VAR Systems for Systems Analysis," Electra, Vol.51, pp.45-74, 1977.

[13] Guohong Wu, Akihiko Yokoyama, Jiali He, and Yixin Yu, "Allocation and Control of FACTS controllers for Steady State Stability Enhancement of Large-Scale Power systems," IEEE Trans on Power Systems, Vol. 13, No.2, 1998.

[14] Malihe M. Farsangi, Hossein Mezamabadi-pour, "Placement of SVCs and Selection of Stabilizing Signals in Power Systems," IEEE Trans. on Power Systems, Vol. 22, No.3, Aug., 2007.

[15] H. F. Wang, "Selection of Robust Installing Locations and Feedback Signals of FACTS Based Stabilizers in Multi-Machine Power systems," IEEE Trans on Power Systems, Vol.14, No.2, May, 1999.

[16] H. Okamoto, A. Kurita, and Y. Seking, "A method for Identification of Effective Locations of Variable Impedance Apparatus on Enhancement of Steady-State Stability in Large Scale Power Systems," IEEE Trans on Power Systems, Vol.10, pp.1401-1407, Aug., 1995.

[17] K. N. Shubhanga, and Anil M. Kulkarni, "Application of Structure Preserving Energy Margin Sensitivity to Determine the Effectiveness of Shunt and Series FACTS Devices," IEEE Trans. on Power Systems, Vol.17, No.3, Aug., 2002.
[18] M. M. Farsang, Y. H. Song, and Kwang Y Lee, "Choice of FACTS device Control Inputs for Damping Inter-area Oscillation," IEEE Trans. on Power Systems, Vol.19, No.2, May, 2004.

[19] N. K. Sharma, A. Ghosh, and R. K. Verma, “A Novel Placement Strategy for FACTS Controllers," IEEE Trans. on Power Delivery, Vol.18, No.3, Jul., 2003.

[20] A. Mohamed and G. B. Jasmon, "Determining the weak Segment of Power System with Voltage Stability Considerations," Electrical Power \& Energy Systems, Vol.24, pp.555-568, 1996.

[21] T. T. Lie, "Method of Identifying the Strategic Placement for Compensation devices," IEEE Trans. on Power Systems, Vol.10, No.3, pp.1448-1453, Aug., 1995.

[22] H. F. Wang , F. J. Swift, and M. Li, "Indices for Selecting the Best Location of PSSs or FACTS Based Stabilizers in Multi-Machine Power Systems: A Comparative Study ," IEE Proc., Pt. C, Vol.144, No.2, pp. 155-159, Mar., 1997.

[23] B. Kalyan Kumar, S. N. Singh and S. C. Srivastava, "Placement of FACTS Controllers Using Modal Controllability indices to Damp out Power System Oscillations," IET Gener. Transm. Distrib. Vol.1, No.2, Mar., 2007.

[24] O. O. Obadina and G. J. Berg, "Identifying Electrically Week and Strong Segments of a Power Systems from a Voltage Stability Viewpoint," IEE Proc. Pt.C, Vol-137, No.3, pp.205-212, May, 1990.

[25] L. A. S. Pilotto, W. W. Ping, A. R. Carvalho, W. F. Long, F. L. Alvarado, C. L. Demarco, and A. Edris, "Coordinated Design of FACTS Controllers to Enhance Power System Dynamic Performance ," International Colloquium on HVDC and FACTS, Johannesburg, Sep., 1997.

[26] N. Martins and L. T. G. Lima, "Determination of Suitable Locations for Power System Stabilizers and Static Var Compensators for Damping Electro-mechanical Oscillation in large Scale Power Systems," IEEE Trans. on Power Systems, Vol.5, No.4, pp.14551469, November 1990.

[27] S. N. Singh and A. K. David, "Placement of FACTS Devices in Open Power Market," Proceeding of the $5^{\text {th }}$ International Conference on Advance in Power System Control, Operation and Management, APSCOM 2000, Hong Kong, pp.173-177, Oct., 2000.

[28] S. N. Singh and A. K. David, "A new approach for placement of FACTS Devices in Open Power Market," IEEE Power Engg. Rev., 2001, 21(9), pp.58-60.

[29] M. K. Verma, and S. C. Srivastava, "Optimal Placement of SVC for Static and Dynamic Voltage Security Enhancement," International Journal of Emerging Electric Power Systems, Vol.2, issue-2, 2005.

[30] J.G. Singh, S. N. Singh, and S. C. Srivastava, "Placement of FACTS Controllers for Enhancing Power System Loadability", IEEE Trans. on Power Delivery, Vol. 12, No.3, Jul., 2006.

[31] Fadela Benzergua, Abdelkader Chaker, Mounir Khiat, and Naima Khalfallah, "Optimal Placement of Static 
VAR Compensator in Algerian Network," Information Technology Journal, Vol.6, No.7, pp.1095-1099, 2007.

[32] S.M. Alamelu, and R. P. Kumudhini Devi, "Novel Optimal Placement UPFC Based on Sensitivity Analysis and Evolutionary Programming," Journal of Engineering and Applied Sciences, Vol.3, No.1, pp.5963, 2008.

[33] Srekanth Reddy Donapati, and M. K. Verma, "An Approach for Optimal Placement of UPFC to enhance Voltage Stability Margin under Contingencies," Fifteenth National Power Systems Conference (NPSC), IIT Bombay, Dec., 2008, pp.441-446.

[34] R. K. Verma, "Control of Static VAR systems for Improvement of Dynamic Stability and Damping of Torsional Oscillations," Ph. D. Thesis, IIT Kanpur, Apr., 1998.

[35] T. Orfano Gianni and R.Bacher, "Steady-State Optimization in Power Systems with Series FACTS Devices," IEEE Trans. on Power Systems, Vol.18, No.1, pp.19-26, Feb., 2003.

[36] W. H. Litzenberger, R. K. Verma and J. D. Flanagan, "An Annotated Bibliography of HVDC transmission and FACTS Devices 1996-1997," Electric Power Research Institute, WO-3022 06 , Jun., 1998.

[37] H. Mehta, T. W. Cease, L. Gyugyi, and C. D. Schauder, "Static Condenser for FACTS," FACTS EPRI Workshop, Boston, Massachusetts, pp.18-22, May, 1992.

[38] Shu Liu, A. R., Messina, and Vijay Vittal, “Assessing Placement of Controllers and Non-linear Behaviour Using Normal Form Analysis," IEEE Trans on Power Systems, Vol.20, No.3, Aug., 2005.

[39] Roberto Mingues, Federico Milano, Rafael ZarateMinano, and Antonio J. Conejo, "Optimal Network Placement of SVC Devices," IEEE Trans. on Power Systems, Vol.22, No.4, Nov., 2007.

[40] Mahbube Zaraatzade, Ivana Kockar, and Yong-Hua Song, "Minimizing Balancing Market Congestion Re-dispatch Cost by Optimal Placement of FACTS Devices," Power Tech., 2007, IEEE Lausanne, 1-5 July, 2007 pp.873-878.

[41] Flavio G. M. Lima, Francisco D. Galiana, Ivana Kockar, and Jorge Munoz, "Phase Shifter Placement in Large Scale Systems Via Mixed Integer Linear Programming," IEEE Trans. on Power Systems, Vol. 18, No.3, Aug., 2003.

[42] Naoto Yorino, E. E. El-Araby, Hiroshi Sasaki, and Shigemi Harada, "A new Formulation for FACTS Allocation for Security Enhancement against Voltage Collapse," IEEE Trans. on Power Systems, Vol.18, No.1, Feb., 2003.

[43] Nuraddeen Magaji, and M. W. Mustafa, "Optimal Location of FACTS devices for damping oscillations using Residue Factor," $2^{\text {nd }}$ IEEE International Conference on power and Energy (PECon 08), December 1-3, 2008, Johor Baharu, Malaysia.

[44] E. J. Oliveira, J. W. M. Lima, and K de. Almeida, "Allocation of FACTS devices in Hydrothermal Sys- tems," IEEE Trans. on Power Systems, Vol.15, No.1, pp. 276-282, Feb., 2000.

[45] C. S. Chang, and J. S. Huang, "Optimal SVC Placement for Voltage Stability Reinforcements," Electric Power System Research, Vol.42, pp.165-172, 1997.

[46] G. Cell, and F. Pilo, "Optimal Sectionalizing Switches Allocations in Distribution Networks," IEEE Trans. on Power Delivery, Vol.14, No.3, Jul., 1999.

[47] Tjing T. Lie and Wanhong Deng, "Optimal Flexible AC Transmission Systems (FACTS) Devices Allocation," Electrical Power \& Energy Systems, Vol.19, No.2, pp.125-134, 1997.

[48] Zuwei Yu, and D. Lusan, "Optimal Placement of FACTS Devices in Deregulated Systems Considering line losses," Electrical Power and Energy Systems, Vol.26, pp.813-819, 2004.

[49] P. Pateni, S. Vitet, M. Bena, and A.Yokoyama, “Optimal Location of Phase Shifters in the French Network by Genetic Algorithm," IEEE Trans. on Power Systems, Vol.14, No.1, pp.37-42, Feb., 1999.

[50] S.Gerbex, R. Cherkaoui, and A.J.Germond, "Optimal Location of Multi-Type FACTS Devices in a Power System by Means of Genetic Algorithms," IEEE Trans. on Power Systems, Vol.16, No.3, pp.537-544, Aug., 2001.

[51] K. Vijakumar, and R.P.Kumudinidevi, "A New Method for Optimal Location of FACTS Controllers Using Genetic Algorithm," Journal of Engineering and Applied Sciences, 2(10), pp.1576-1580, 2007.

[52] Mohd WAzir Mustafa, and Wong Yan Chiew, "Optimal Placement of Static VAR Compensator Using Genetic Algorithms," Elektrika, Vol.10, No.1, pp.2631, 2008.

[53] S. N. Singh, and I. Erlich, "Locating Unified Power Flow Controllers for Enhancing Power System Loadability," Future Power Systems, 2005, International Conference, 18 Nov., 2005, pp.5-5.

[54] H. C. Leung, and T. S. Chung, "Optimal Placement of FACTS Controllers in Power Systems by a Genetic Based Algorithm," IEEE 1999 International Conf. on Power Electronics and Drive Systems, PEDS'99, July 1999, Hong Kong.

[55] Lijun Cai, Istvan Erlich, Georgios Stamtsis, and Yicheng Luo, "Optimal Choice and Allocation of FACT Devices in Deregulated Electricity Market Using Genetic Algorithms," Bulk Power Systems Dynamics and Control, VI, August 22-27, 2004, Cortinad' Ampezzo, Italy.

[56] H.I. Shaheen, G. I. Rashed, and S.J. Cheng, "Optimal Location and Parameters Setting of UPFC based on GA and PSO for Enhancing Power System Security Under Single Contingencies," Power and Energy Society General Meeting-Convesion and delivery of Electrical Energy in The $21^{\text {st }}$ Century, 2008, IEEE, 20-24 July, 2008, pp.1-8.

[57] L. Ippolito, "A novel Strategy for Selection of the Optimal Number and Location of UPFC devices in Deregulated Electric Power Systems," Power Tech, 
2005, IEEE Russia, 27-30 June, 2005, pp.1-9.

[58] K. Vijayakumar, and R. P. Kumudinidevi, "A New Method for Optimal Location of FACTS Controllers Using Genetic Algorithms," Journal of Theoretical and Applied Information Technology, 2005-2007 JATIT.

[59] Hassan Barati, Mehdi Ehsan, and Mahmud FotuhiFiruzabad, "Location of Unified Power Flow Controller and its Parameters Setting for Congestion Management in Pool Market Model Using Genetic Algorithm," Power Electronics, Drives and Energy Systems, 2006, PEDES'06, International conference, 12-15 Dec., 2006, pp.1-7.

[60] Songpakit Kaewniyompanit, Yasunori Mitani, and Kiichiro Tesuji, "A method of micro-GA Combined Neighboring Search for Approaching to an Optimal Type Selection and Placement of a FACTS device for Power System Stabilizing Purpose in a Multi-machine power System," 2004 International Conference on Power Systems Technology-POWERCON 2004, Singapore, 21-24 Nov., 2004.

[61] L.J. Cai, I. Erlich, and G. Stamtsis, "Optimal Choice and Allocation of FACTS Devices in Deregulated Electricity Market Using Genetic Algorithms," In Proc., 2005, IEEE Power Engg. Soc., General Meeting, pp.201-207.

[62] E. E. El-Araby, N. Yorino, and H. Saraki, "A Comprehensive Approach of FACTS Devices Optimal Allocation to Mitigate Voltage Collapse," In Proc., 2002, IEEE Transmission and Distribution Conf. Exhib, pp.62-67.

[63] Z. Y. Dong, Y. Wang, D. J. Hill, and Y. V. Makarov, "A New Approach to Power Systems VAr Planning Aimed at Voltage Stability Enhancement with Feedback Control," In Proc. 1999, Electric Power Engineering Power Tech. Budapest '99, pp.33-39.

[64] L. Ippolito, and P. Siano, "Selection of Optimal Number and Location of Thyristor Controlled Phase Shifters Using Genetic Based Algorithms," In Proc., Inst. Elect. Engg., Gen., Transm., Distrb., Vol.151, No.5, pp.630637, Sep., 2004.

[65] P.Bhasaputra and W. Ongsakul, "Optimal Placement of Multi-Type FACTS Devices by Hybrid TS/SA Approach," Circuits and Systems, 2003, International Symposium on, Vol.3, 25-28 May, 2003, pp III 375III 378.

[66] H. Mori, and Y. Goto, "Parallel Tabu Search Based Method for Determining Optimal Allocation of FACTS in Power Systems," In Proc., Power Conf. on Power System Technology, 2000, pp.1077-1082.

[67] W.L.Fang, and H. W. Ngan, "Optimizing location of UPFC using the Methods of Augmented Lagrange Multipliers," IEE Proc., Gener., Transm.,Distrib., Vol 146, No.5, Sep., 1999.

[68] J. Hao, L. B. Shi, and Ch. Chen, "Optimizing location of UPFC by means by Improved Evolutionary Programming," IEE Proc., Gener., Transm., Distrib., Vol.151, No.6, Nov., 2004.

[69] M. Gitizadeh, and M. Kalanta, "A New Approach for
Congestion Management via Optimal Location of FACTS Devices in Deregulated Power Systems," DRPT 2008, 6-9 Apr., 2008, Nanjing China.

[70] S. Gerbex, R. Cherkaui, and A. J. Germond, “Optimal Location of FACTS Devices to Enhance Power Systems Security," In Proc., 2003, IEEE Bologria Power Tech. Conf., pp.23-26.

[71] K. Chandrasekaran, K. Arul Jey Araj, L. Sahayasenthamil, and M. Saravanan, "A New Method to Incorporate FACTS Devices in Optimal Power Flow Using Particle Swarm Optimization," Journal of Theoretical and Applied Information Technology, 2005-2009, JATIT.

[72] G. I Rashed, H. I. Shaheen, and S. T. Cheng, "Optimal Location and Parameter Setting of TCSC by Both Genetic Algorithm and Particle Swarm Optimization," 2007, IEEE Second conf. on Industrial Electronics and Applications, China.

[73] Adel Moradi, and M. Fotuhi-Firuzabad, "Optimal Switch Placement in Distribution Systems Using Trinary Particle Swarm Optimization Algorithm," IEEE Trans. on Power Delivery, Vol.23, No.1, Jan., 2008.

[74] L. Gyugi, N. G. Hingorani, P. R. Nannery, and N. Tai, "Advanced Static VAR Compensator Using Gate Turn-off Thyristor for Utility Applications," CIGRE, 23-203, 1990 Session, Paris.

[75] T. S. Dillon, “Artificial Neural Network Applications to Power Systems and Their Relationship to Symbolic Methods," Electrical Power \&Energy Systems., Vol.13, No.2, pp.66-72, 1991.

[76] P. K. Das, S. Saha, and P.K. Nanda, “Artificial Neural Network Approach for Capacitor Placement in Power Systems," In Proc., Ist. Int. Forum on Application of Neural Networks to Power Systems, 1991, pp.247250 .

[77] Hamid Falaghi, M. Reza Halhifam, and Chanan Singh, "Ant Colony Optimization Based Method for Placement of Sectionalizing Switches in distribution networks Using a Fuzzy Multi- Objective Approach," IEEE Trans. on Power Delivery, Vol.24, No.1, Jan., 2009.

[78] J. F. Gomez, H. M. Khodr, P. M. De Oliveira, L. Ocqul, J. M. Yusta, R. Villasana, and A. J. Urdaneta, "Ant Colony System Algorithm for the Planning of Primary Distribution Circuits," IEEE Trans on Power Systems, Vol.19, No.2, May, 2004.

[79] J. C.Carlisle, and A. a. El Keib, "A Graph Search Algorithm for Optimal Placement of Fixed and Switched Capacitors on Radial Distribution System," IEEE Trans. on Power Delivery, Vol.15, No.1, Jan., 2000.

[80] M Saravanan, S. Mary Raja Slochanal, P. Venkatesh, P. S. Abraha, "Application of PSO Technique for Optimal Location of FACTS Devices Considering Systems Loadability and Cost of Installation," Power Engineering Conference, 2005, IPEC 2005, The $7^{\text {th }}$ International Conference, 29 Nov 2005- 2 Dec 2005, pp.716-721.

[81] K. Visakha, D. Thukaram, L. Jenkins, and H.P. Khin- 
cha, "Selection of UPFC Suitable Locations for System Security Improvement Under Normal and Network Contingencies," TENCON 2003, Conference on Convergent Technologies for Asia -Pacific Region, Vol-2, 15-17 Oct., 2003, pp.755-760.

[82] D. Thukarana, L. Jenkins, and K. Visakha, "Improvement of System Security with UPFC at Suitable Locations Under Network Contingencies of Interconnected Systems," IEE Proc., Gener., Transm., Distrib., Vol.152, No.5, Sep., 2005.

[83] Jing Zhang, J. Y. Wen, S. J. Cheng, and Jia Ma, "A Novel SVC Allocation Method for Power System Voltage Stability Enhancement by Normal Forms of Diffeomorphism," IEEE Trans. on Power Systems, Vol.22, No.4, Nov., 2007.

[84] M. Santiago-Luna, and J. R. Cedeno-Maldonado, "Optimal Placement of FACTS Controllers in Power Systems via Evolution Strategies," 2006 IEEE PES Transmission and Distribution Conf. and Exposition Latin, America, Venezuela.

[85] Esmat Rashedi, Hossien Nezamabadi-Pour, Saeid Saryazdi, ansd Malihe M. Farsangi, "Allocation of Static VAR Compensator Using Gravitational Search Algorithm," First Joint Congress on Fuzzy and Intelligent Systems Ferdowsi University of Mashhad, Iran, 29-31 August 2007.

[86] R.P.Kalyani, M. L. Crow, and D. R. Tauritz, "Optimal Placement and Control of UPFC devices Using Evolutionary Computing and Sequential Quadratic Programming," Power Systems Conference and Exposition 2006, PSCE'06, 2006 IEEE PES, 29 Oct., 20061 Nov., 2006, pp 959-964.

[87] J. E. Candelo, N. G. Caicedo, and F.Castro Aranda, "Proposal for the Solution Voltage Stability Using Coordination of FACTS Devices," 2006, IEEE PES Transmission and Distribution Conf. and Exposition Latin America, Venezuela.

[88] F. P.Demello, P. J. Nolan, T. P. Laskowski, and J. M. Undrill, "Coordinated Application of Stabilizers in Multi-machine Power Systems," IEEE Trans. on Power Apparatus \&Systems, Vol.PAS-99, No.3, May/June 1980.

[89] A.Doi, and S. Abe, "Coordinated Synthesis of Power Systems Stabilizers in multi-machine Power Systems," IEEE Trans. on Power Apparatus \& Systems, Vol.-PAS-103, No.6, Jun., 1984.

[90] O.H., Abdalle, S. A. Hassan, and N. T. Tweig, "Coordinated Stabilization of a multi-machine Power Systems," IEEE Trans on Power Apparatus \& Systems, Vol.-PAS-103, No.3, Mar., 1984.

[91] E. Z. Zhou, O. P. Malik, and G. S. Hope, "Design of Stabilizer for a multi-machine Power Systems based on the Sensitivity of PSS Effect," IEEE Trans on Energy Conversion, Vol.7, No.3, Sep., 1993.

[92] L Xu, and S. Ahmed Zaid, "Tuning of Power System Controllers Using Symbolic Eigen Sensitivity Analysis and Linear Programming," IEEE Trans. on Power Systems, Vol.10, No.1, February 1995.
[93] K.W. Wang, C. Y. Chung, C. T. Tse, and K. M. Tsag, "Multi-machine Eigen Value Sensitivity of Power System Parameters," IEEE Trans on Power Systems, Vol.15, No.2, May, 2000.

[94] N.K.Sharma, "A Novel Placement Strategy for FACTS Controllers in Multi-machine Power Systems," Ph. D. Thesis, IIT Kanpur, India, 2003.

[95] C. Y. Chung, K. W. Wang, C. T. Tse, X. Y. Bian, and A. K. David, "Probabilistic Eigen value Sensitivity Analysis and PSS Design in Multi-machine Power Systems," IEEE Trans on Power Systems, Vol.18, No 4, Nov., 2003.

[96] Juan M. Ramirez, Isidro Castillo, "PSS and FDS simultaneous tuning," Electric Power Systems Research, Vol.68, pp.33-40, 2004.

[97] Mao-Xiaoming, Zhang Yao, Guan Lin, and Wu Xiaochen, "Coordinated Control of Inter-area Oscillation in the China Southern Power Grid," IEEE Trans on Power Systems, Vol.21, No.2, May, 2006.

[98] C.L. Chen and Y. Y. Hsu, "Coordinated Synthesis of Power System Stabilizers Using An Efficient Decentralized Modal Control (DMC) Algorithm," IEEE Trans. on Power Systems, Vol.PWRS-2., No.3, pp. 543-551, Aug., 1987.

[99] R. M. Hamouda, M. R. Iravani, and R. Hacham, "Coordinated Static VAR Compensators for Damping Power System Oscillations," IEEE Trans. on Power Systems, Vol.PWRS-2, No.4, Nov., 1987.

[100]F. Luis Pagola, Ignacio, J. Perez-Arriaga, and George C. Varghese, "On Sensitivities, residues and Participations: Applications to Oscillatory Stability Analysis and Control," IEEE Trans on Power Systems, Vol.4, No.1, Feb., 1989.

[101] Yasuyu Ki Tada, Hiroyuk, Ohkubo, and Atsushi Kurita, "Multi-variables Control Design for Damping Inter-area Oscillation of Bulk Power Systems Using a Modal Reduction Technique," IEEE Trans. on Power Systems, Vol.11, No.1, Feb., 1996.

[102] A Elices, L. Rouco, H. Bourles, and T. Margotin, "Design of Robust Controllers for Damping Inter-area Oscillations: Application to the European Power System," IEEE Trans on Power Systems, Vol.19, No.2, May, 2004.

[103] J. J. Sanchez- Gasca and J. H. Chow, "Power systems Reductions to Simplify the Design of Damping controllers for Inter-area Oscillations," IEEE Trans on Power Systems, Vol.11, No.3, pp.1342-1349, Aug., 1996.

[104]A. R. Messina, O. Begovich, J. H. Lopez, E. N. Reyes, "Design of Multiple FACTS controllers for Damping inter-area oscillations: a decentralized control approach," Electrical Power \& Energy Systems, Vol.26, pp.19-29, 2004.

[105] Sami Ammari, Yuon Besanger, Nourdine Hadjsaid, and Dider Georges, "Robust Solution for the Interaction Phenomena between Dynamic loads and FACTS controllers," IEEE Trans on Power Systems, Vol.15, No.2, 2000.

[106]P Shrikant Rao, and I. Sen, “ Robust Pole Placement 
Stabilizers Design Using Linear Matrix Inequalities," IEEE Trans on Power Systems, Vol.15, No.1, Feb., 2000 .

[107] S.S. Choi and X. M. Jia, "Coordinated Design of Under Excitation Limiters and Power System Stabilizers," IEEE Trans on Power Systems, Vol.15, No.3, Aug., 2000 .

[108]K Bollinger, A. Laha, R. Hamilton, and T. Harras, "Power Stabilizer Design Using Root Locus Methods," IEEE Trans on Power Apparatus \& Systems, Vol. PAS-94, No.5, September/October 1975.

[109] J.J. Sanchez-Gasca, "Coordinated Control of two FACTS devices for Damping Inter-area Oscillations," IEEE Trans. on Power Systems, Vol.13, No.2, pp.428-434, May, 1998.

[110] Yu. T. and So. P. L., "Coordinated Control of TCSC and SVC for System Damping Improvement," Proc. Int. Cont on Electric Utility Deregulation and Restructuring and Power Technologies (DRPT) London UK, 2000, pp.7-12.

[111] Ping Lam So, Yun Chung Chu, and Tao Yu, "Coordinated Control of TCSC and SVC for system Damping Enhancement," International Journal of Control Automation and Systems, Vol.3, No.2, (special edition), pp.322-333, June 2005.

[112] Yoke Lin Tan and Youyi Wang, "Design of series and shunt FACTS controllers using Adaptive nonlinear coordinated design techniques," IEEE Trans on Power Systems, Vol.12, No.3, Aug., 1997.

[113] Youyi wang, Yoke Lin Tan, and Guoxiao Guo, "Robust Non-linear Coordinated Excitation and SVC Control for Power Systems," In Proc. of the $4^{\text {th }}$ International Conf. on Advances in Power System Control, Operation and Management, APSCOM'97, Hong Kong, Nov., 1997.

[114] A. J. A. Simoes Costa, F. D. Freitas, and A. S. Silva, "Design of Decentralized Controllers for Large Power Systems Considering Sparsity," IEEE Trans on Power Systems, Vol,12, No.1, Feb., 1997.

[115] J. V. Milanovic, and I. A. Hiskens, "Damping Enhancement by Robust Tuning of SVC Controllers in the Presence of load Parameters Uncertainty," IEEE Trans on Power Systems, Vol.13, No.4, Nov., 1997.

[116] Claudio A. Canizares, and Zeno T. Faur, "Analysis of SVC and TCSC Controllers in Voltage Collapse," IEEE Trans on Power Systems, Vol.14, No.1, Feb., 1999.

[117] G. Li, T.T. Lie, G. B. Shrestha and K. L.Lo, "Design and Application of Coordinated multiple FACTS Controllers," IEE Proc. Gener., Transm., Distrib., Vol. 147, No.2, Mar., 2000.

[118] Rajat Majumder, Bikash C. Pal, Christan Dufour, and Petr Korba, "Design and Real Time Implementation of Robust FACTS Controller for Damping Inter-area Oscillation," IEEE Trans on Power Systems, Vol.21, No.2, May, 2006.

[119] G. Li, T. T. Lie, G. B. Shrestha and K. L. Lo., "Implementation of Coordinated multiple FACTS Con- trollers for Damping Oscillations," Electrical Power and Energy Systems, Vol.22, pp.79-92, 2000.

[120]Fan Li, Baohua Li, and Xujun Zheng, "Coordination of Power Flow Control in Large Power Systems," IEEE Trans on Power Systems Vol.16, No.4, Nov., 2001.

[121]S. Khannan, Shesha Jayaram, and M.M. A Salama, "Real and Reactive Power Coordination for a Unified Power Flow Controller," IEEE Trans on Power Systems, Vol.19, No.3, Aug., 2004.

[122] Sandro Corsi, Massimo, Pozzi, Carlo Sabelli, and Antonio Serrani, "The Coordinated Automatic Voltage Control of the Intalian Transmission Grid Part I: Reasons of the Choice and Overview of the Consolidate Hierarchical System," IEEE Trans on Power Systems, Vol.19, No.4, Nov., 2004.

[123]Hai Feng wang, H. Li, and H. Chen, "Coordinated Secondary Voltage Control to Eliminate voltage Violations in Power System Contingencies," IEEEE Trans on Power Systems, Vol.18, No.2, May, 2005.

[124] Shu Fan, Cheng Xiog Mao, and Luonan Chen, “ Optimal Coordinated PET and Generator Excitation Control for Power Systems," Electrical Power and Energy Systems, Vol.28, pp.158-165, 2006.

[125] Ahmadreza Tabesh, and Reza Iravani, "Multi-variable Dynamic Model and Robust Control of a Voltage Source Converter for Power System Applications," IEEEE Trans on Power Delivery, Vol.24, No.1, Jan., 2009.

[126] Gabriela Hug-Glanzmann, and Goran Andersson, "Decentralized Optimal Power Flow Control for Overlapping Areas in Power Systems," IEEE Trans Power Systems, Vol.24, No.1, Feb., 2009.

[127]M.R. Iravani, “A Software Tool for Coordination of Controllers in power Systems," IEEE Trans on Power Systems, Vol.5, No.1, Feb., 1990.

[128] A. R.Mahran, B. W. Hogg, and M. L. El. Sayed, "Coordinated Control of Synchronous Generator Excitation and Static VAR Compensator," IEEE Trans on Energy Conversion, Vol.7, No.4, Dec., 1992.

[129]Hong, Ying-Yi, and Wu Wen-Ching, "A New Approach Using Optimization for Tuning Parameters of Power System Stabilizers," IEEE Trans on Energy Conversion, Vol.14, No.3, Sep., 1999.

[130]X. Zhou and J. Liang, "Non-linear Adaptive Control of the TCSC to Improve the Performances of Power Systems," IEE Proceedings on Generation, Transmission, and Distribution, Vol.146, No.3, May, 1999, pp. 301-305.

[131]X. Lei, E. N. Lerch, and D. Povh, "Optimization and Coordination of Damping Controls for Improving System Dynamic Performance," IEEE Trans. on Power Systems, Vol.16, pp.473-480, Aug., 2001.

[132] Rodrigo A Ramos, Andre. C. P. Martins, and Newton G. Bretas, "An Improved Methodology for the Design of Power System Damping Controllers," IEEE Trans. on Power Systems, Vol.20, No.4, Nov., 2005.

[133]L. J. Cai, and I. Erlich, "Simultaneous Coordinated 
Tuning of PSS and FACTS Damping Controllers in Large Power Systems," IEEE Trans. on Power Systems, Vol.20, No.1, Feb., 2005.

[134]C. P. Chen, O. P. Malik, Y. H. Qin, and G. Y. Xu, "Optimization Techniques for the Design of a Linear Optimal Power System Stabilizers," IEEE Trans on Energy Conversion, Vol.7, No.3, Sep., 1992.

[135]P. Pourbeik and M. J. Gibbard, "Simultaneous Coordination of Power System Stabilizers and FACTS Devices Stabilizers in Multi-Machine Power System for Enhancing Dynamic Performance," IEEE Trans. on Power Systems, Vol.13, No.2, pp.473-479, 1998.

[136]Zhihong Feng, Ven Kataramana Ajjarapu, and Dominic J. Maratukulam, “A Comprehensive Approach for Preventive and Corrective Control to Mitigate Voltage Collapse," IEEE Trans on Power Systems, Vol.15, No.2, May, 2000.

[137]L. I. Yan -Jun, Hill David J., and W. U. Tie-Jun, “Optimal Coordinated Voltage Control of Power Systems," Journal of Zhejiang University Science A, Vol. 7, No.2, pp.257-262, 2006

[138] Innocent Kamwa, Gilles Trudel, and Luc GerinLajoie, "Robust Design and Coordination of Multiple Damping Controllers Using Non-linear Constrained Optimization, "IEEE Trans on Power Systems, Vol.15, No.3, Aug., 2000.

[139]I. Roytelman, and V. Ganesan, "Coordinated Local and Centralized Control in Distribution Management Systems," IEEE Trans. on Power Delivery, Vol.15, No.2, Apr., 2000

[140]G. Glanzmann, and G. Anderson, "Coordinated Control of FACTS Devices Based on Optimal Power Flow," IEEE Trans. on Power Systems, Vol.19, No.1, Feb., 2004.

[141]Rodrigo A Ramos, Luis F. C., Alberto, and Newton G. Bretas, "A New Methodology for the Coordinated Design of Robust Decentralized Power System Damping Controllers," IEEE Trans. on Power Systems, Vol.19, No.1, Feb., 2004.

[142] CIGRE Working Group 14-29, "Coordination of Controls of Multiple FACTS/HVDC Links in the same power system," CIGRE Technical Brochure, No.149, Paris, Dec., 1999.

[143] Gabriela Hug-Glanzmann, and Goran Anderson, "Coordinated Control of FACTS Devices in Power Systems For Security Enhancement," IERP Symposium, Bulk Power System Dynamics and Control, VII, Revitalizing Operational Reliability, Charleston, SC, USA, Aug., 19-24, 2000.

[144]P. Zhang and A. H. Coonick, "Coordinated Synthesis of PSS Parameters in Multi-Machine Power Systems Using the Method of Inequalities Applied to Genetic Algorithms," IEEE Trans. on Power Systems, Vol.15, No.2, May, 2000.

[145]A L. B. do Bomfim, G. N. Taranto, and D. M. Falcao, "Simultaneous Tuning of Power Systems Damping Controllers Using Genetic Algorithms," IEEE Trans. on Power Systems, Vol.15, No.1, Feb., 2000.
[146] Keshi Reddy, Saidi Reddy, Narayana Prasad Padhy, and R. N. Patel, "Congestion Management in Deregulated Power System Using FACTS Devices," IEEE Trans. on Power Systems, Vol.21, No.2, 2006.

[147] Siddhartha Panda and Narayana Prasad Padhy, "Power System with PSS and FACTS Controllers: Modeling, Simulation and Simultaneous Tuning Employing Genetic Algorithms," International Journal of Electrical Computer and System Engineering, Vol.1, No.1, 2007.

[148] Y. L. Abdel Magid, M. A. Abido, and A. H. Mantaway, "Robust Tuning of Power System Stabilizers in Multimachine Power Systems," IEEE Trans on Power Systems, Vol.15, No.2, May, 2000.

[149]M. A. Abido, "Simulated Annealing Based Approach to PSS and FACTS Based Stabilizers Tuning," Electrical Power and Energy Systems, Vol.22, pp.247-258, 2000.

[150] Siddhartha Panda and Narayana Prasad Padhy, "Coordinated Design of TCSC Controllers and PSSS Employing Particle Swarm Optimization Technique," International Journal of Computer and Information Science and Engineering, Vol.1, No.1, 2006.

[151]Pavel Etingov, Alexandre Oudalov, Nikolai Voropai, Rachid Cherbaoui, and Alain Germond, " Power System Stability Enhancement Using ANN Based Coordinated Emergency Control System," In Proc. Of the IEEE Power Tech. 2007, Lauzanne, Switzerland, July $1-5,2007$,

[152]Juan M. Raminrez, Ricardo J. Davalos, Abraham, Valenzuela, and Ixtlahuate Coronado, "FACTS Based Stabilizers Coordination," Electrical Power and Energy Systems, Vol.124, pp.233-243, 2002.

[153]M.O.Sadegh and K.L.Lo "Method for Co-ordinated application of FACTS-based stabilizers in multimachine power system using fuzzy out put feedback controller," IEE Proc.-Gener., Transm., Distrib., Vol. 152, No.3, May, 2005.

[154]L. J. Cai, and I. Erlich, "Fuzzy Coordination of FACTS Controllers for Damping Power Oscillations," IEEE Trans. on Power Systems, Vol.21, No.3, 2006.

[155]A. Oudalov and P. Korba, "Coordinated Power Flow Control Using FACTS Devices," ABB Switzerland Ltd. Corporate Research, Switzerland, 2005.

[156]L. J. Cai, and I. Erlich, "Coordination Between Transient and Damping Controller for Series FACTS Devices Using ANNFIS Technology," IEE Proc., Gener., Transm., Distrib., Vol.152, No.3, May, 2005.

[157] Shu Liu, A.R. Messina, Vijay Vithal "A Normal Form Analysis Approach to Siting Power System Stabilizers (PSS) and Assessing Power System Nonlinear Behavior," IEEE Trans on Power Systems, Vol.21, No.4, Nov., 2006.

[158]Dheeman Chatterjee and Arindam Ghosh, "Application of Trajectory Sensitivity for the Evaluation of the Effect of TCSC Placement on Transient Stability," International Journal of Emerging Electric Power Systems, Vol.8, Issue 1, 2007.

[159]U.P.Mhaskar, and A. M. Kulkarni, "Power Oscillation 
Damping Using FACTS Devices: Modal Controllability, Observability in Local signals, and Location of Transfer Function Zeros,” IEEE Trans on Power Systems, Vol.21, No.1, Feb., 2006.

[160] Seungwon An, John Codren and W.Gedra, "An Ideal Transformer UPFC Model, OPF First-Order Sensitivities, and Application to Screening for Optimal UPFC Locations," IEEE Trans on Power Systems, Vol.22, No.1, Feb., 2007.

[161] S.M. Alamelu, and R. P. Kumudhini Devi, "Novel Optimal Placement of UPFC Based on Sensitivity Analysis and Evolutionary Programming," Journal of Engineering and Applied Sciences 3(1), 59-63, 2008.

[162] V.Ajjarapu, Ping Lin Lau, and S. Battula, "An Optimal Reactive Power Planning Strategy Against Voltage Collapse," IEEE Trans on Power Systems, Vol.9, No. 2, May, 1994.

[163]T. Jain, S. N. Singh, and S.C. Srivastava, "Dynamic ATC Enhancement Through Optimal Placement of FACTS Controllers," Electric Power System Research, Vol. 79, Issue 11, May, 2009, pp.1473-1482.

[164] Srinivasa Rao Pudi, and S.C.Srivastava, "Optimal Placement of TCSC Based on A Sensitivity Approach for Congestion Management," Fifteenth National Power Systems Conference (NPSC), IIT Bombay, Dec., 2008, pp.558-563.

[165]C. A. Canizares, A. Berizzi, and P. Marannino, "Using FACTS Controllers to Maximize Available Transfer Capability," Bulk Power Systems Dynamics and Control, IV-Restructuring, Aug., 24-28, 1998, Santorim, Greece.

[166]L. Rouco, and F.L. Pagola, "An Eigen-value Sensitivity Approach to Location and Controller Design of Controllable Series Capacitors for Damping Power System Oscillations," IEEE Trans on Power Systems, Vol.12, No.4, Nov., 1997.

[167]J. G. Singh, S. N. Singh, and S. C. Srivastava, "Optimal Placement of Unified Power Flow Controller Based on System Loading Distribution Factors," Electric Power Components and Systems, Vol.37, Issue 4, Apr., 2009, pp.441-463

[168]Nuraddeen Magaji, and M. W. Mustafa, "Optimal Location of TCSC Device for Damping Oscillations," ARPN Journal of Engineering and Applied Sciences, Vol.4, No.3, May, 2009.

[169]M. W. Mustafa, Nuraddeen Magaji, and "Optimal Location of Static Var Compensator Device for Damping Oscillations," American Journal of Engineering and Applied Sciences, Vol.2, No.2, 2009.

[170] Ashwani kumar Sharma,"Optimal Number and Location of TCSC and Loadability Enhancement in Deregulated Electricity Markets Using MINLP," International Journal of Emerging Electric Power Systems, Vol.5, Issue 1, 2006.

[171] Guang Ya Yang, Geir Hovland, Rajat Mujumder, and Zhao Yang Dong, "TCSC Allocation Based on Line Flow Based Equations Via Mixed-Integer Programming," IEEE Trans on Power Systems, Vol.22, No.4,
Nov., 2007

[172] A hybrid Meta-Heuristic Method for Optimal Allocation of UPFCs," Circuits and Systems, 2009, ISCAS 2009, IEEE International Symposium, 24-27 May, 2009, pp.1705-1708.

[173] Tina Orfanogianni, and Rainer Bacher, "Steady-State Optimization in Power Systems with Series FACTS Devices," IEEE Trans on Power Systems, Vol.18, No.1, Feb., 2003.

[174]F.F. Moghaddam, H.Nezamabadipour, and Malihe M. Farsangi, "Curved Space Optimization for Allocation of SVC in a Large Systems," in Proc. Of the $6^{\text {th }}$ Conference on Application of Electrical Engineering, Istanbul, Turkey, 2007, pp.59-64.

[175]Baskaran Jeevarathinam, "Genetic Algorithm and Fuzzy Logic Based Optimal Location of FACTS Device in a Power System Network," International Journal of Emerging Electric Power Systems, Vol.5, Issue 2, 2006.

[176] Lucio Ippolito, Antonio La Cortiglia, and Michele Petrocelli, "Optimal Allocation of FACTS Devices by Using Multi-Objective Optimal Power Flow and Genetic Algorithms," International Journal of Emerging Electric Power Systems, Vol.7, Issue 2, 2006.

[177] Yuan-Lin Chen, "Weak Bus-Oriented Optimal MultiObjective VAR Planning," IEEE Trans on Power Systems, Vol.11, No.4, Nov., 1996.

[178] Ying-Yi Hong, and Chen-Ching Liu, "A heuristic and Algorithmic Approach to VAR Planning," IEEE Trans on Power Systems, Vol.7, No.2, May, 1992.

[179] Toan Dang Nguyen, Didier Georges, and Quoc Tuan Tran, "An Energy Approach for the Placement of Controllers \& Sensors in a Power Systems," International Journal of Emerging Electric Power Systems, Vol.9, Issue 6, 2008.

[180]L. J. Cai, I. Erlich, and G. Stamtsis, "Optimal Choice and Allocation of FACTS Devices in Deregulated Electricity Market Using Genetic Algorithms," Power Systems Conference and Exposition, 2004, IEEE PES, Vol-1, 10-13 OCT, 2004, pp.201-207.

[181] Shen J., Liu C., Yokoyama R., and Ishimaru M., "Coordinated Control of PSS and FACTS for Poor Damping long-term Oscillations in Multi-machine Power Systems," $39^{\text {th }}$ International Universities Power Engineering Conference, University of the West of England(UWE), Bristol, UK, 6-8 Sep., 2004.

[182]P. Etingov, N. Voropai, A. Oudalov, A. Germond, and R. Cherkaoui, "Congestion Management Using Coordinated Control of FACTS Devices and Load Shedding," $15^{\text {th }}$ PSCC, Liege, 22-26, Aug., 2005.

[183] A.J. Urdanata, N. J. Bacalao, B. Feijoo, L. Flores, and R. Diaz, "Tuning of Power System Stabilizers Using Optimization Techniques," IEEE Trans on Power Systems, Vol.6, No.1, Feb., 1991.

[184] A. M. Simoes, D. C. Savelli,P. C. Pellanda, N. Martins, and P. Apkarian ,"Robust Design of a TCSC Oscillation Damping Controller in a Weak 500-kV Interconnection Considering Multiple Power Flow Sce- 
narios and External Disturbances," IEEE Trans on Power Systems, Vol.24, No.1, Feb., 2009.

[185]A. Hasanovic, Ali Feliachi, Azra Hasanovic, N. B. Bhatt, and A. G. DeGroff, "Practical Robust PSS Design Through Identification of Low-Order Transfer Functions," IEEE Trans on Power Systems, Vol.19, No.3, Aug., 2004.

[186] Y.L. Abdel-Magid, M.A. Abido, S. Al-Baiyat, A.H. Mantawy, "Simultaneous Stabilization of Multi-machine Power Systems via Genetic Algorithms," IEEE Trans on Power Systems, Vol.14, No.4, Nov., 1999.

[187]I. Ngamroo, "Robust Frequency Stabilization By Coordinated Superconducting Magnetic Energy Storage With Static Synchronous Series Compensator," International Journal of Emerging Electric Power Systems, Vol.3, Issue 1, 2005.

[188] Sadegh, Mahmoud Outkati, Lo. K. L., "Decentralized coordination of FACTS for Power System Stability enhancement Using Intelligent Programming," International Journal for Computation and Maths in Electrical Engg., Vol.24, No.1, 2005, pp.179-201(23).

[189] J.M.Ramirez, R. J. Davalos, A. Valenzuela, and I. Coronado, "FACTS-based Stabilizers Coordination," International Journal of Electrical Power \& Energy Systems, Vol.24, Issue 3, March 2002, pp.233-243.

[190] S. Panda, N. P. Pandy, and R. N. Patel, "Robust Coordinated Design of PSS and TCSC Using PSO Technique for Power System Stability Enhancement," Journal of Electrical Systems, 3-2(2007), pp.109-123.

[191]G. N. Taranto, and Joe H. Chow, "A Robust Frequency Domain Optimization Technique for Tuning Series Compensation Damping Controllers," IEEE Trans on Power Systems, Vol.10, No.3, Aug., 1995.

[192] O. Zhao, and Jin Jiang "Robust SVC Controllers Design for Improving Power System Damping," IEEE Trans on Power Systems, Vol.10, No.4, Nov., 1995.

[193]B. Chaudhuri, and B. C. Pal, "Robust Damping of Multiple Swing Modes Employing Global Stabilizing Signals with a TCSC," IEEE Trans on Power Systems, Vol.19, No.1, Feb., 1999.

[194]X. Yu, M. Khammash, and V. Vittal, "Robust Design of a Damping Controller for Static Var Compensators in Power Systems," IEEE Trans on Power Systems, Vol.16, No.3, Aug., 2001.

[195] M. Yue, and R. Schlueter, "Robust Control Design for Multiple Bifurcations," IEEE Trans on Power Systems, Vol.20, No.1, Feb., 2005.

[196] M.Yue, and R. A. Schlueter, “ $\mu$-Synthesis Power System Stabilizer Design Using a Bifurcation Subsystem Based Methodology," IEEE Trans on Power Systems, Vol.18, No.4, Nov., 2003.

[197] G.E. Boukarim, S. Wang, Joe H. Chow, G. N. Taranto, and N. Martins, "A Comparison of Classical, Robust, and Decentralized Control Designs for Multiple Power System Stabilizers," IEEE Trans on Power Systems, Vol.15, No.4, Nov., 2000.

[198]D. J. Trudnowski, J. R. Smith, T. A. Short, and D. A.
Pierre, "An Application of Prony methods in PSS Design for Multi-Machine Power Systems," IEEE Trans on Power Systems, Vol.6, No.1, Feb., 1991.

[199]A. S. Bazanella, and A. S. E Silva, "Coordinated Design of Damping Controllers for Robustness of Power Systems Stability," Int. J. of Electrical Power\& Energy Systems, Vol.23, Issue 1, Jan., 2001.

[200] Y. Chang, "Design of HVDC and SVC Coordinate Damping Controller Based on Wide Area Signal," International Journal of Emerging Electric Power Systems, Vol.7, Issue 4, 2006.

[201]C. P. Gupta, "Voltage Stability Margin Enhancement using FACTS controllers," Ph. D. Thesis, IIT Kanpur, Oct., 2000.

[202]T. T. Nguyen, and R. Gianto, "Neural Networks for Adaptive Control Coordination of PSSs and FACTS Devices in Multi-machine power system," IET Gener. Transm. Distrib, 2008, Vol.2, No.3, pp355-372.

[203]T. T. Nguyen, and R. Gianto, "Optimization-based Control Coordination of PSSs and FACTS Devices for Optimal Oscillations Damping in multi-machine power system," IET Gener. Transm. Distrib, 2007, Vol.1, No.4, pp.564-573.

[204]T. T. Nguyen, and R. Gianto, “ Stability Improvement of Electromechanical Oscillations by Control Coordination of PSSs and FACTS Devices in Multimachine Power Systems," Power Engineering Society General Meeting 2007, IEEE 24-28 Jun., 2007, pp.1-7.

[205] Sidhartha Panda, and C. Ardil, "Robust Coordinated Design of Multiple Power System Stabilizers Using Particle Swarm Optimization Technique," International Journal of Electrical and Electronics Engineering, Vol.1, No.1, 2008.

[206] M. Najafi, and A. Kazemi, "Coordination of PSS and FACTS Damping controllers in Large power Systems for Dynamic Stability Improvement," Power System Technology, 2006, POWERCON'2006, International Conference, 22-26 Oct., 2006, pp.1-6.

[207]C. Rehtanz, and U. Hager, "Coordinated Wide Area Control of FACTS for Congestion Management," Electric Utility Deregulation and Restructuring and Power Technologies, 2008, DRPT-2008, $3^{\text {rd }}$ International Conference, 6-9 Apr., 2008, pp.130-135.

[208]Liu Jun, Tang Guangfu, and Li Xingyuan, "Interaction Analysis and Coordination Control between SSSC and SVC," Power System Technology, 2006, POWERCON'2006, International Conference, 22-26 Oct., 2006, pp.7-10.

[209] Karim Sebaa, and Mohamed Boudour, "Power System Dynamic Stability Enhancement via Coordinated Design of PSSs and SVC -based Controllers Using Hierarchical Real Coded NSGA-II," Power \&Energy Society General Meeting -Conversion \& Delivery of Electrical Energy in the $21^{\text {st }}$ Century 2008, IEEE, 2024 July, 2008, pp.1-8.

[210] J. W. Park, R. G. Harley, and G. K. Vanayagamoorthy, "Power System Optimization and Coordination of Damping Controllers by Series FACTS Devices," 
Power Engineering Society Inaugural Conference \& Exposition in Africa 2005, IEEE, 11-15 July, 2005, pp.293-298.

[211]H. W. Ngan W. Fang, "Coordinated Power Control Strategy for Flexible Ac Transmission System," Power Electronics \& Drive Systems, 1999, PEDS'99 Proceedings of the IEEE 1999 International Conference, Vol.2, 27-29 July, 1999, pp.677-682.

[212]Liu Qing, and W. Zengzing, "Coordinated Design of Multiple FACTS Controllers Based on Fuzzy Immune Co-evolutionary Algorithm," Power \&Energy Society General Meeting,2009, PES'09, IEEE, 26-30 Jul., 2009, pp1-6.

Bindeshwar Singh received the M.Tech. in electrical engineering from the Indian Institute of Technology, Roorkee, in 2001.He is now a Ph. D. student at UPTU, Lucknow, India. His research interests are in Coordination of FACTS controllers in multi-machine power systems and Power system Engg. Currently, he is an Assistant Professor with Department of Electrical Engineering, Kamla Nehru Institute of Technology, Sultanpur,U.P., India, where he has been since August '2009.
Nikhlesh Kumar Sharma received the Ph.D. in electrical engineering from the Indian Institute of Technology, Kanpur, in 2001. Currently, he is a Director with, Raj Kumar Goel Engineering College, Pilkhuwa, Ghaziabad, U.P., India, where he has been since June' 2009. His interests are in the areas of FACTS control and Power systems.

A.N.Tiwari received the $\mathrm{Ph} . \mathrm{D}$. in electrical engineering from the Indian Institute of Technology, Roorkee, in 2004. Currently, he is an Asst. Prof. with Department of Electrical Engineering, Madan Mohan Malviya Engineering College, Gorakhpur,U.P., India, where he has been since June'1998. His interests are in the areas of Electrical Drives and Application of Power Electronics. 